\title{
Modification of fluid inclusions in quartz by deviatoric stress I: experimentally induced changes in inclusion shapes and microstructures
}

\author{
Alexandre Tarantola • Larryn W. Diamond • \\ Holger Stünitz
}

Received: 18 August 2009/Accepted: 25 February 2010/Published online: 24 March 2010

(C) Springer-Verlag 2010

\begin{abstract}
Fluid inclusions in quartz are known to modify their shapes and microstructures (textures) during weak plastic deformation. However, such changes have not been experimentally demonstrated and criteria are not available to relate them to paleostress conditions. To address these issues, quartz crystals containing natural $\mathrm{CO}_{2}-\mathrm{H}_{2} \mathrm{O}-\mathrm{NaCl}$ fluid inclusions have been experimentally subjected to compressive deviatoric stresses of 90-250 MPa at $700^{\circ} \mathrm{C}$ and $\sim 600 \mathrm{MPa}$ confining pressure. Strains of up to $1 \%$ cause the inclusions to develop irregular shapes and to generate microcracks in crystallographic planes oriented subperpendicular to the major compression axis, $\sigma_{1}$. The uniform alignment of the microcracks imparts a planar fabric to the samples. The microcracks heal and form swarms of tiny satellite
\end{abstract}

Communicated by J.L.R. Touret.

Electronic supplementary material The online version of this article (doi:10.1007/s00410-010-0509-z) contains supplementary material, which is available to authorized users.

A. Tarantola $(\bowtie) \cdot$ L. W. Diamond

Rock-Water Interaction Group, Institute of Geological Sciences,

University of Bern, Baltzerstrasse 3, 3012 Bern, Switzerland

e-mail: Alexandre.Tarantola@g2r.uhp-nancy.fr

H. Stünitz

Department of Geology, University of Troms $\varnothing$,

Dramsveien 201, 9037 Troms $\varnothing$, Norway

Present Address:

A. Tarantola

UMR-G2R, Université Henri Poincaré,

54506 Vandoeuvre-lès-Nancy Cedex, France inclusions. These new inclusions lose $\mathrm{H}_{2} \mathrm{O}$ by diffusion, thereby triggering plastic deformation of the surrounding quartz via $\mathrm{H}_{2} \mathrm{O}$-weakening. Consequently, the quartz samples deform plastically only in domains originally rich in inclusions. This study shows that fluid inclusions deformed by deviatoric stresses may indeed record information on paleostress orientations and that they play a key role in facilitating crystal-plastic deformation of quartz.

Keywords Crystal-plasticity - Hydrolytic weakening · Deformation · Fluid inclusion · Reequilibration ·

Microstructure

\section{Introduction}

Studies of fluid inclusions in undeformed minerals have yielded important information on the composition, density and evolution of paleo-fluids in the Earth's Crust (e.g. Roedder 1984). Quartz has been by far the most commonly examined host mineral, owing to its ubiquity, transparency, propensity to trap inclusions (favourable wetting characteristics) and good fluid retentivity (poor cleavage). Where there is good evidence that the volume and composition of the fluid inclusions have not changed since entrapment, reconstruction of the paleofluid properties is usually straightforward using an isochoric-isoplethic model. Less tractable are the fluid inclusions for which post-entrapment modifications of inclusion shape, volume and composition are either suspected or are patently obvious. Experimental studies over recent years have advanced understanding of the microstructural changes induced by variations in hydrostatic confining pressure (Gratier and Jenatton 1984; Pêcher and Boullier 
1984; Boullier et al. 1989; Sterner and Bodnar 1989; Vityk and Bodnar 1995; Vasyukova and Fonarev 2006). Recognition of the characteristic microstructures in natural samples has permitted reconstruction of the history of pressure evolution in the host rocks (Vityk et al. 1994, 1996; Ayllon et al. 2003; Hurai et al. 2008; Mukherjee and Sachan 2009; Stöckhert et al. 2009).

In addition to the effects of hydrostatic stresses, it has long been known that plastic deformation driven by deviatoric (shear) stresses can also modify fluid inclusions in quartz. Based on petrographic studies of natural samples, Kerrich (1976) and Wilkins and Barkas (1978) suggested that fluid inclusions in plastically deforming quartz may leak and that recrystallization of the host mineral causes inclusions to migrate to grain boundaries, where the fluid is released to an open system. Plastically deformed quartz grains therefore typically contain fewer and smaller inclusions than adjacent undeformed crystals. In the extreme case where shearing has led to wholesale recrystallization of the quartz, the new subgrains are devoid of inclusions.

Plastically deformed quartz is of utmost interest to studies of crustal rheology, tectonics, metamorphism and hydrothermal ore deposits. Low-strain samples from these environments often contain abundant fluid inclusions that could potentially yield useful information on paleofluids and on deformation histories. However, there have been no studies that have defined the nature and extent of inclusion modifications caused by low degrees of strain prior to recrystallization of the host quartz.

To provide more understanding of these effects, we have experimentally subjected inclusion-bearing, natural single quartz crystals to uniaxial compression within the regime of crystal plasticity (Griggs 1967; Hirth and Tullis 1992; Stipp et al. 2002). Comparison of the fluid inclusions before and after the experiments has permitted identification of the modifications induced by the deformation. This article describes the modifications of shapes and microstructures observed in the experiments ("microstructure" is used herein as an equivalent of the traditional petrological term "texture"). A companion article (Diamond et al. 2010) reports the changes in fluid inclusion volumes and composition in the same set of experiments.

The present article begins with an outline of the experimental approach and a detailed description of the applied methods. The results of preparatory experiments performed under hydrostatic stress and of the final target experiments performed under deviatoric stress are then presented. Based on these results, the modifications of the fluid inclusion shapes and microstructures can be generalized for the case of low strain deformation.

\section{Experimental methods}

\section{Experimental approach}

The experiments were carried out on natural, individual, undeformed quartz crystals that contain abundant $\mathrm{CO}_{2}-$ $\mathrm{H}_{2} \mathrm{O}-\mathrm{NaCl}$ fluid inclusions. The inclusions were first mapped and analysed to record their positions, shapes, chemical compositions and densities. The samples were then placed in a solid-medium, Griggs-type, piston-cylinder apparatus and subjected to various hydrostatic or deviatoric stresses. To enable deformation by axial shortening in the crystal-plastic regime, the quartz samples were held at elevated temperature and elevated hydrostatic confining pressure. Once under these conditions the samples were compressed uniaxially by applying a constant load for periods of 12-136 h. After subsequently decompressing and cooling the samples, the inclusions were analysed again to reveal any modifications of their properties.

Although simple in principle this approach turned out to be difficult to follow in practice. Four important issues had to be addressed. First, because the $\alpha / \beta$-transition of quartz is associated with a volume increase and it is known to enhance plastic deformation (Schmidt et al. 2003), the experiments had to be conducted within the $\alpha$-quartz field to avoid any stresses that are unrelated to the simple uniaxial compression. When combined with the $P-T$ slopes of the fluid inclusion isochores, this constraint limited the temperature of the experiments to $\sim 700^{\circ} \mathrm{C}$ or less. Given these low temperatures and the rather high strain rates of the experiments, the deformation achieved was not purely plastic but in part semi-brittle.

Second, the effects of deviatoric stress - the focus of this study-had to be isolated from any background effects of differential hydrostatic pressure. At high temperatures, fluid inclusions undergo changes in volume, shape and even composition if their internal pressure is significantly different from the hydrostatic confining pressure (Gratier and Jenatton 1984; Pêcher and Boullier 1984; Sterner and Bodnar 1989; Vityk and Bodnar 1995). The aim was therefore to run the deformation experiments with a difference in hydrostatic pressure (difference between the fluid inclusion pressure and the confining pressure; $\left.\Delta P=P_{\text {inc }}-P_{\text {conf }}\right)$ equal to zero. The obvious way to attain these conditions is to first determine the bulk molar volume (or density) of the inclusions, and using an appropriate equation of state (EoS), calculate the $P-T$ locus of the corresponding fluid isochore, taking account of the expansivity and compressibility of the host quartz. In the present case, the pertinent fluid isochore is a line with a constant slope in $P-T$ space. By heating the sample and simultaneously adjusting the confining pressure so as to 
follow this calculated $P-T$ gradient, the fluid inclusions ideally never experience a difference in pressure. At all points along the isochoric path $P_{\text {inc }}=P_{\text {conf }}$ and therefore $\Delta P=0$. However, this approach pre-supposes that all the inclusions are characterized by the same isochore. In our samples, the inclusions display a small natural range of densities and compositions. Therefore, they do not all follow exactly the same isochore upon heating and hence they do not all experience exactly the same internal pressure at a given experimental temperature. Consequently, several test experiments had to be run, guided by calculations of isochores in $P-T$ space, to find a hydrostatic confining pressure that matched the internal pressure of most of the target inclusions at the temperature selected for the final experiments $\left(700^{\circ} \mathrm{C}\right)$. Once this pressure was found ( $\sim 600 \mathrm{MPa}$ ) the uniaxial compression experiments could be performed without the inclusions additionally suffering from hydrostatic over- or underpressures.

Third, even knowing the optimum isochoric path to follow, procedures still had to be developed to insert, compress, decompress and retrieve the delicate inclusionbearing samples without causing additional artefacts due to mechanical stresses within the apparatus. Numerous runs were therefore performed to optimize the run-up and rundown procedures, the microthermometric properties of the inclusions being monitored before and after each test. Although not all the artefacts of compression (e.g. vertical mode-I cracks) and decompression (e.g. horizontal extension fractures) could be eliminated, their effects could be minimized such that they did not interfere with the essential objectives of the experiments.

Fourth, as the Griggs apparatus generates significant quantities of $\mathrm{H}_{2}$ (e.g. Brooker et al. 1998), diffusion of $\mathrm{H}_{2}$ into the fluid inclusions (e.g. Morgan et al. 1993; Hall and Sterner 1995) had to be prevented. Addition of $\mathrm{H}_{2}$ changes the gas speciation and thereby alters the temperatures of phase transitions within the inclusions, precluding our intended use of the transition temperatures to monitor the effects of deviatoric stress. This problem was solved by placing $\mathrm{Fe}_{2} \mathrm{O}_{3}$ powder near the experimental samples.

In the following sections, the experimental samples and procedures are described in detail, and observational proof is given of our solutions to the aforementioned practical issues.

\section{Quartz samples}

Quartz plates for the experiments were cut from single, euhedral, freely grown crystals from hydrothermal veins at the Fenilia gold mine, Brusson, NW Italian Alps, as described by Diamond (1990; sample LD888). The selected crystals are $1.5-2.5 \mathrm{~cm}$ thick and $4-7 \mathrm{~cm}$ long. They display sharp optical extinction in cross-polarized,
Table 1 Main glide systems in quartz oriented along $\mathrm{O}^{+}$

\begin{tabular}{lll}
\hline Glide plane & & Glide direction \\
\hline$m\{10 \overline{1} 0\}$ & Prism & $c<0001>$ \\
& & $a<\overline{1} 2 \overline{1} 0>$ \\
& & $c+a<\overline{1} 2 \overline{1} 3>$ \\
$c(0001)$ & Basal & $a<\overline{1} 2 \overline{1} 0>$ \\
$r\{01 \overline{1} 0\}$ & $(+)$ rhomb & $a<\overline{1} 2 \overline{1} 0>$ \\
$z\{0 \overline{1} 10\}$ & & $c+a<\overline{11} 23>$ \\
& $(-)$ rhomb & $a<\overline{1} 2 \overline{1} 0>$ \\
& & $c+a<\overline{11} 23>$
\end{tabular}

Glide systems are sorted with decreasing Schmidt factor according to e.g. Baëta and Ashbee 1969; Morrison-Smith et al. 1976; Lister et al. 1978; Blacic and Christie 1984; Doukhan and Trépied 1985; Vernooij et al. 2006

transmitted light and delicate growth-banding in cathodoluminescence. Healed brittle fractures are common, but there are no features indicative of plastic deformation.

The crystals contain abundant fluid inclusions within the size range (5-50 $\mu \mathrm{m}$ diameter) appropriate for our experiments. Smaller and larger inclusions are also present. Several generations of inclusions are represented, most being secondary and pseudosecondary. Some inclusions within healed fractures show a weak preferred orientation of their major axes owing to crystallographic control of the host quartz, but the orientations of most inclusions are scattered. All the inclusions used in the experiments were originally trapped from a homogeneous (1 phase) fluid. Although crystals from the same veins also contain heterogeneously trapped inclusions, namely $\mathrm{CO}_{2}$-rich "vapour" inclusions coexisting with immiscible $\mathrm{CO}_{2}$-poor "liquid" inclusions (Diamond 1990), these were purposefully excluded from the experiments.

At room temperature, the inclusions consist of three fluid phases: a weakly saline aqueous liquid containing 4.0-5.5 mass\% salts (dominantly $\mathrm{NaCl}$ ) and a bubble of carbonic liquid enclosing a bubble of carbonic vapour. The carbonic phases are dominated by $\mathrm{CO}_{2}$ with minor $\mathrm{N}_{2}(3-$ $4 \mathrm{~mol} \%)$ and trace $\mathrm{CH}_{4}(<0.07 \mathrm{~mol} \%)$. Some inclusions contain accidentally captured crystallites of muscovite or dolomite. The bulk composition is 90.4-92.2 mol\% $\mathrm{H}_{2} \mathrm{O}$ and $6.4-4.6 \mathrm{~mol} \% \mathrm{CO}_{2}$, the remainder being chloride salts and minor gases. The quartz crystals were formed in open cavities at temperatures between 225 and $300^{\circ} \mathrm{C}$. Further details are given by Diamond (1990).

The quartz crystals were oriented prior to cutting by reference to their well-developed prism faces. An orientation was chosen that facilitates plastic deformation by uniaxial compression, in compliance with the main slip systems of quartz (Table 1). Thus, the maximum resolved shear stress is obtained for basal $\langle a\rangle$ and prismatic $\langle c\rangle$ glide systems when the quartz is cut at $45^{\circ}$ to 
the basal plane and to the $c$ axis, with one of the $a$-axes down-dip in the section (e.g., Baëta and Ashbee 1969; Blacic and Christie 1984). This orientation is termed $\mathrm{O}^{+}$. The crystals were cored in this orientation with a diamond drill to yield rods of $\sim 6.5 \mathrm{~mm}$ diameter and 2 to $\sim 14 \mathrm{~mm}$ length. These were then sliced into plates $1.9-2.3 \mathrm{~mm}$ thick and manually polished to obtain faces that were parallel to within $\pm 0.002 \mathrm{~mm}$ over the entire sample.

\section{Piston-cylinder experiments}

Experiments were performed in the Rock Deformation Laboratory of the Geological Institute of the University of Basel using a standard, solid-medium, Griggs-type pistoncylinder apparatus (Fig. 1). This equipment allows samples to be heated to high temperature and subjected to two types of stress regimes. First, high hydrostatic stresses can be imposed, resulting in the present case in purely elastic deformation of the inclusion-bearing quartz samples. Second, in addition to the hydrostatic confining pressure, uniaxial compressive stress can be applied along the vertical axis of the sample, resulting in the present case in semi-brittle deformation that leads into crystal-plasticity (details given in Discussion). The difference between the axial compressive stress $\left(\sigma_{1}\right)$ and the hydrostatic confining pressure $\left(\sigma_{3}\right)$ gives the deviatoric stress $\left(\Delta \sigma=\sigma_{1}-\sigma_{3}\right)$.

All sample assembly pieces were individually manufactured with opposite plane-parallel faces $(\leq 0.002 \mathrm{~mm}$ for alumina pistons and $\leq 0.01 \mathrm{~mm}$ for salt pieces). The solid salt assembly (Fig. 1) fits into a 25.4-mm sample chamber of the pressure vessel (not shown in Fig. 1). The quartz sample was placed within a short gold tube with gold spacer discs and alumina pistons on either side (Fig. 1b). For some experiments, powdered $\mathrm{Fe}_{2} \mathrm{O}_{3}$ was set around each alumina piston to act as a redox buffer $\left(\mathrm{H}_{2}\right.$ sink $)$ during the high $T$ experiments. Gold lids were welded in place above and below to create a sealed capsule (Fig. 1b). The samples were held in liquid nitrogen during welding to avoid deforming or decrepitating the fluid inclusions by heating. The capsule was then inserted into an inner salt liner, which is separated from two larger, outer salt sleeves by a graphite furnace stabilized by two soft-fired, pyrophyllite sleeves. To avoid differential stresses acting on the sample during the initial application of confining pressure, a $\sim 2 \mathrm{~mm}$ salt disc was introduced between the two upper alumina pistons. In addition, an empty space was left between the upper lead and alumina pistons to accommodate some movement during pressurization. These
Fig. 1 a Schematic vertical section (to scale) of the solidmedium, Griggs-type, pistoncylinder apparatus used to deform quartz crystals containing fluid inclusions. b Vertical section of sample capsule in perspective view. Axial compression axis $\sigma_{1}$ is vertical; radial confining stress $\sigma_{3}$ is horizontal
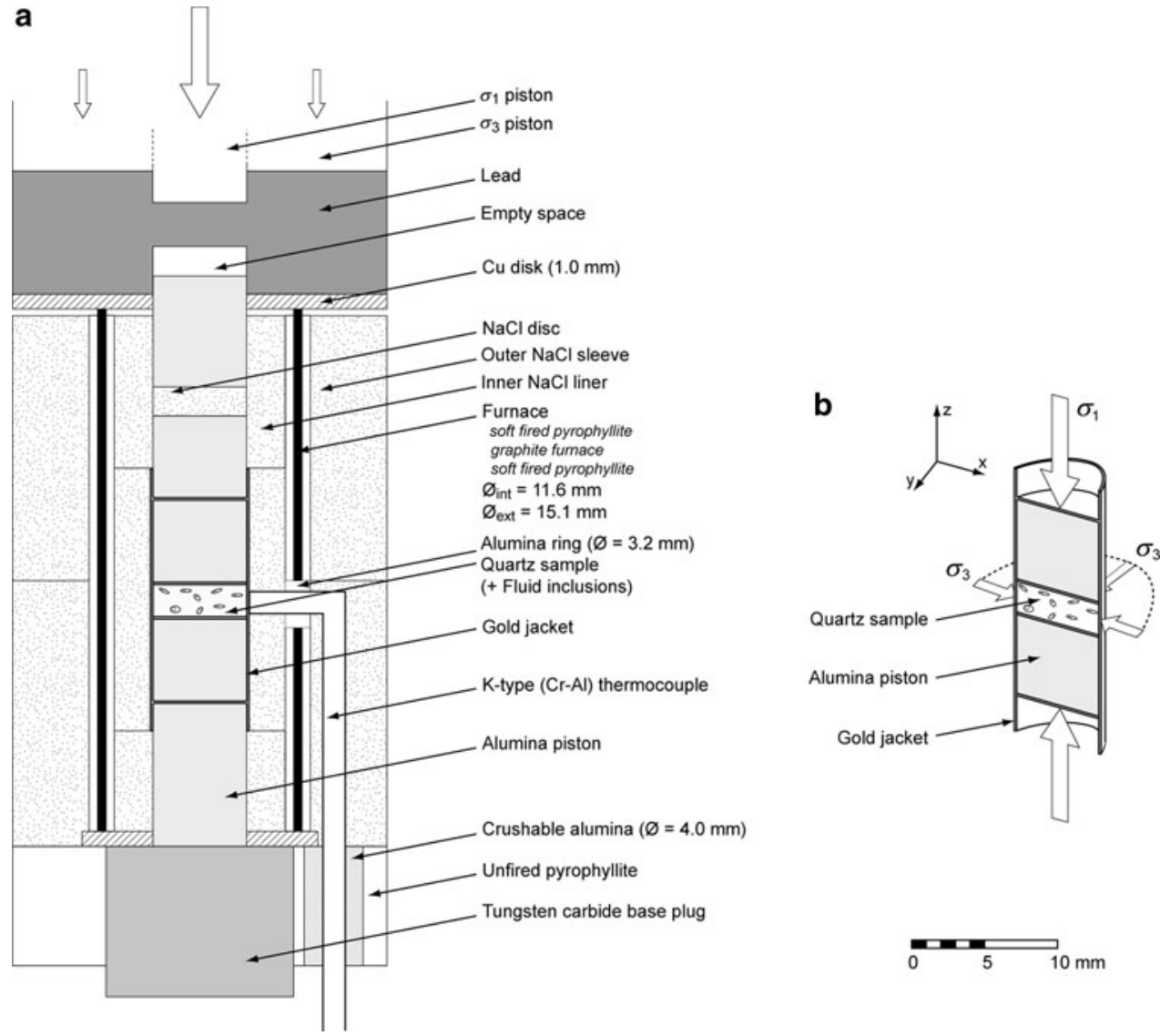


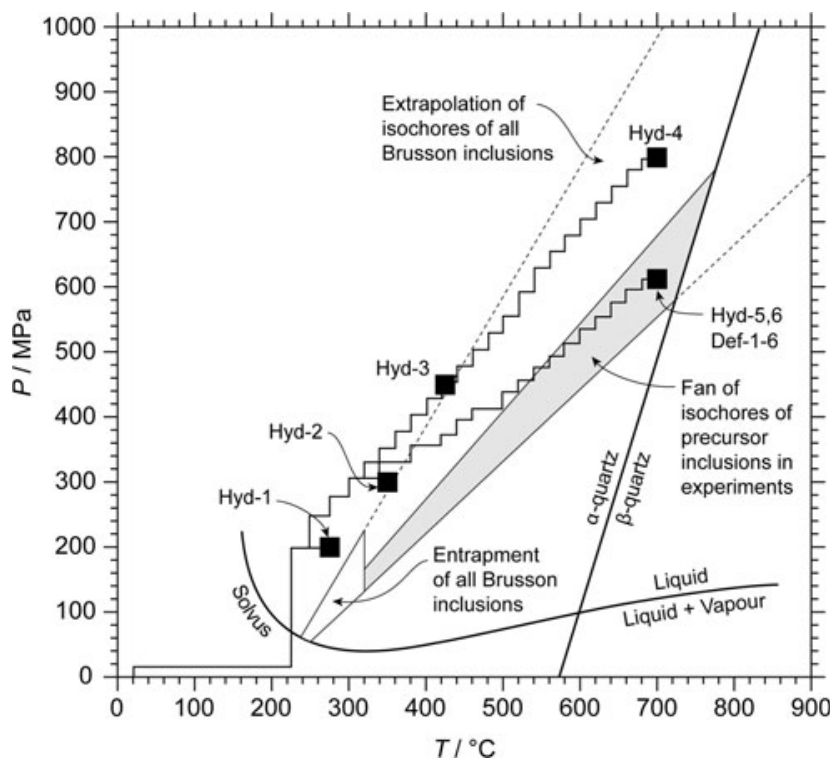

Fig. $2 P-T$ conditions of hydrostatic experiments (squares labelled Hyd-) and deformation experiments involving deviatoric stresses (square labelled Def-). Stepped paths show compression-heating and decompression-cooling trajectories of experiments. Fan of isochores delineating entrapment conditions of all inclusions from Brusson sample locality is taken from Diamond (1990). Extrapolation of fan yields hypothetical internal pressures of all inclusions at $700^{\circ} \mathrm{C}$. Shaded fan of isochores represents subset of inclusions used as "precursors" in experiments. Inclusions in experiment Hyd-4 (800 MPa) experienced negative differential pressure $\left(P_{\text {inc }} \ll P_{\text {conf }}\right)$. Inclusions in Hyd-5,6 and Def-1-6 (600 MPa) experienced negligible differential pressure $\left(P_{\text {inc }} \approx P_{\text {conf }}\right)$. Quartz phase boundary from Hosieni et al. (1985). Approximate position of fluid solvus interpolated from data in Gehrig (1980) and Krüger and Diamond (2001)

precautions help prevent axial loading of the sample while the salt assembly is still hard (below $200-300^{\circ} \mathrm{C}$ ), the aim being to maintain purely hydrostatic pressure.

The assembly was first heated to $225^{\circ} \mathrm{C}$ with a constant heating rate $\left(\sim 6^{\circ} \mathrm{C} \cdot \mathrm{min}^{-1}\right)$ and held at this temperature and at 10-20 MPa for $10 \mathrm{~min}$. Previous heating-stage tests had showed that the largest inclusions decrepitate under $1 \mathrm{~atm}$ confining pressure at temperatures above $225^{\circ} \mathrm{C}$. To avoid decrepitation in the piston cylinder at higher temperatures, the confining pressure was gradually increased to $200 \mathrm{MPa}$ over $\sim 2 \mathrm{~h}$ and the assembly was left at $225^{\circ} \mathrm{C}$ and $200 \mathrm{MPa}$ for $10 \mathrm{~min}$. Temperature was then increased in steps of 20 or $40^{\circ} \mathrm{C}$ and pressure in steps of $25 \mathrm{MPa}$ (or in steps of $20 \mathrm{MPa}$ above $350 \mathrm{MPa}$ and $380^{\circ} \mathrm{C}$ ) at a rate of approximately $6^{\circ} \mathrm{C} \cdot \mathrm{min}^{-1}$ until the target $P-T$ conditions for the experiment were reached (stepped paths in Fig. 2). For the deformation experiments, the axial compression was increased gradually towards the target stress over the course of 0.75 to $2.5 \mathrm{~h}$, and then held constant for the duration of the experiment (i.e. constant-load mode; values determined from the hit-point in the $\sigma_{1}$-time chart).

The experimental temperature was kept constant at $700^{\circ} \mathrm{C}$ with a small variation of $\pm 1^{\circ} \mathrm{C}$. Owing to the short sample length of $2 \mathrm{~mm}$, the temperature gradient is quite small $\left(<10-15^{\circ}\right.$ lower at the sample ends at $\left.700^{\circ} \mathrm{C}\right)$. The absolute pressure experienced by the sample is less well constrained, the uncertainty possibly being as high as $\pm 50 \mathrm{MPa}$ (from pressure calibrations by R.A. Yund and J. Tullis; pers. comm. J. Tullis). Uniaxial differential stress resolution is assumed to be on the order of $\pm 20 \%$ at the stress levels attained.

The decompression-cooling path to room $P-T$ conditions followed the same steps and timing in reverse (Fig. 2). After each experiment, the quartz samples and the alumina pistons typically contain horizontal cracks that formed during decompression. Sample strains were determined from measurements of sample lengths in thin-section, subtracting the widths of the extension cracks. This rather approximate procedure yielded strains in the order of $1 \%$. Average bulk strain rates were calculated directly from the estimated strain and the duration of the experiments at the target $P-T$ or $\sigma-T$ conditions.

\section{Characterization of fluid inclusions prior to experiments}

Between 50 and 720 fluid inclusions were selected per sample to represent a range in shape, size and distance to
Fig. 3 Nomenclature of fluid inclusions modified by deviatoric stresses

Before experiment


Table 2 Experimental conditions and main observations of hydrostatic experiments

\begin{tabular}{lllllll}
\hline Exp. & Basel lab no. & $\mathrm{Fe}_{2} \mathrm{O}_{3}$ buffer & $T\left({ }^{\circ} \mathrm{C}\right)$ & $P(\mathrm{MPa})$ & Duration (hours) & Comments \\
\hline Hyd-1 & 124AT & No & 275 & 200 & 16 & No decrepitation, no shape changes \\
Hyd-2 & $125 \mathrm{AT}$ & $\mathrm{No}$ & 350 & 300 & 17 & No decrepitation, no shape changes \\
Hyd-3 & $126 \mathrm{AT}$ & $\mathrm{No}$ & 425 & 450 & 17 & No decrepitation, no shape changes \\
Hyd-4 & $129 \mathrm{AT}$ & $\mathrm{No}$ & 700 & 800 & 16 & Irregular-shaped inclusions, 3D-haloes \\
Hyd-5 & 130AT & No & 700 & 600 & 16 & Euhedral inclusions \\
Hyd-6 & 139AT & Yes & 700 & 600 & 139 & Euhedral inclusions \\
\hline
\end{tabular}

Table 3 Experimental conditions of deformation experiments at $700^{\circ} \mathrm{C}$

\begin{tabular}{lllllllll}
\hline Exp. & Basel lab no. & $\begin{array}{l}\mathrm{Fe}_{2} \mathrm{O}_{3} \\
\text { buffer }\end{array}$ & $\begin{array}{l}\text { Duration }^{\mathrm{a}} \\
\text { (hours) }\end{array}$ & Strain $^{\mathrm{b}}(\%)$ & $\begin{array}{l}\text { Strain rate } \\
\left(\mathrm{s}^{-1}\right)\end{array}$ & $\begin{array}{l}\text { Confining pressure } \\
\left(\sigma_{3}\right)(\mathrm{MPa})\end{array}$ & $\begin{array}{l}\text { Compressive } \\
\text { stress }\left(\sigma_{1}\right)(\mathrm{MPa})\end{array}$ & $\begin{array}{l}\text { Nominal dev. } \\
\text { stress } \Delta \sigma(\mathrm{MPa})\end{array}$ \\
\hline Def-1 & 163AT & Yes & 110 & $<0.2$ & $<5 \times 10^{-9}$ & 613 & 705 & 92 \\
Def-2 & 149AT & Yes & 136 & $0.1-0.3$ & $<6 \times 10^{-9}$ & 615 & 750 & 135 \\
Def-3 & 161AT & Yes & 110 & $0.3-0.6$ & $<2 \times 10^{-8}$ & 616 & 778 & 866 \\
Def-4 & 133AT & No & 133 & $<1.0$ & $<2 \times 10^{-8}$ & 614 & 836 & 252 \\
Def-5 & 132AT & No & 12 & $0.2-0.4$ & $<9 \times 10^{-8}$ & 614 & 847 & 222 \\
Def-6 & 152AT & Yes & 17 & $?$ & $?$ & 630 & & 217 \\
\hline
\end{tabular}

a Time at target $P-T$ conditions of experiment

${ }^{b}$ Plastic strain measured from difference in sample height before and after experiment

the sample surface. The inclusions were numbered and individually photographed and their positions were mapped to permit relocation after the experiments. Microthermometric measurements were made on a subset of the mapped inclusions. To avoid any deformation or leakage of the inclusions prior to the experiments, the samples were held below $35^{\circ} \mathrm{C}$. Therefore, the total homogenization temperatures, known from Diamond (1990) to lie in the range $225-270^{\circ} \mathrm{C}$, were not measured. The three-dimensional orientation of the fluid inclusions was measured on oriented sections using a four-axis universal stage mounted on a standard Zeiss ${ }^{\mathrm{TM}}$ microscope.

\section{Results}

The results of the two series of experiments (hydrostaticand deviatoric-stress) are presented separately in the following paragraphs. Details of microthermometry are given in the companion paper (Diamond et al. 2010). Figure 2 shows the corresponding $P-T$ conditions of the experiments. To identify the orientation of photographs in the accompanying figures, the vertical axis during the experiment is denoted by $z$ (= $\sigma_{1}$-direction), and the horizontal axes by $x$ and $y$ (normal to $\sigma_{1}$ ).

In many of the experiments, the inclusions split apart and they adopted new microstructures. To facilitate their description, the following nomenclature is used (Fig. 3): "Intact" inclusions are those that survived as single objects during the experiments, regardless of any changes in shape; "Dismembered" inclusions usually generate a "cluster" of inclusions consisting of a recognizable "relict" of the "precursor" surrounded by smaller "neonate" inclusions that formed entirely during the experiments.

\section{Hydrostatic scoping experiments}

Tables 2 and 3 list experimental conditions and key observations pertaining to the series of hydrostatic experiments (labelled with prefix "Hyd-"). The results of three experiments run at $700^{\circ} \mathrm{C}$ are described in the following paragraphs.

Experiment Hyd-4 (unbuffered) was conducted at $800 \mathrm{MPa}$ for $16 \mathrm{~h}$. After the experiment, all the inclusions had adopted irregular shapes with rough walls (Fig. 4a, b). Three-dimensional clusters of tiny satellite neonates had also formed around the relicts of the precursor inclusions (Fig. 4c). The changes in microthermometric properties are consistent with an increase in density but complicated by the influx of $\mathrm{H}_{2}$ (Diamond et al. 2010).

Experiment Hyd-5 (unbuffered) was conducted at $600 \mathrm{MPa}$ for $16 \mathrm{~h}$. No major changes in shapes of the inclusions were observed except for a tendency towards smoother walls. Changes in microthermometric properties were observed, but these are attributable solely to influx of $\mathrm{H}_{2}$ (Diamond et al. 2010).

Experiment Hyd-6 was performed to verify the results of Hyd-5 over a longer time period and without the 


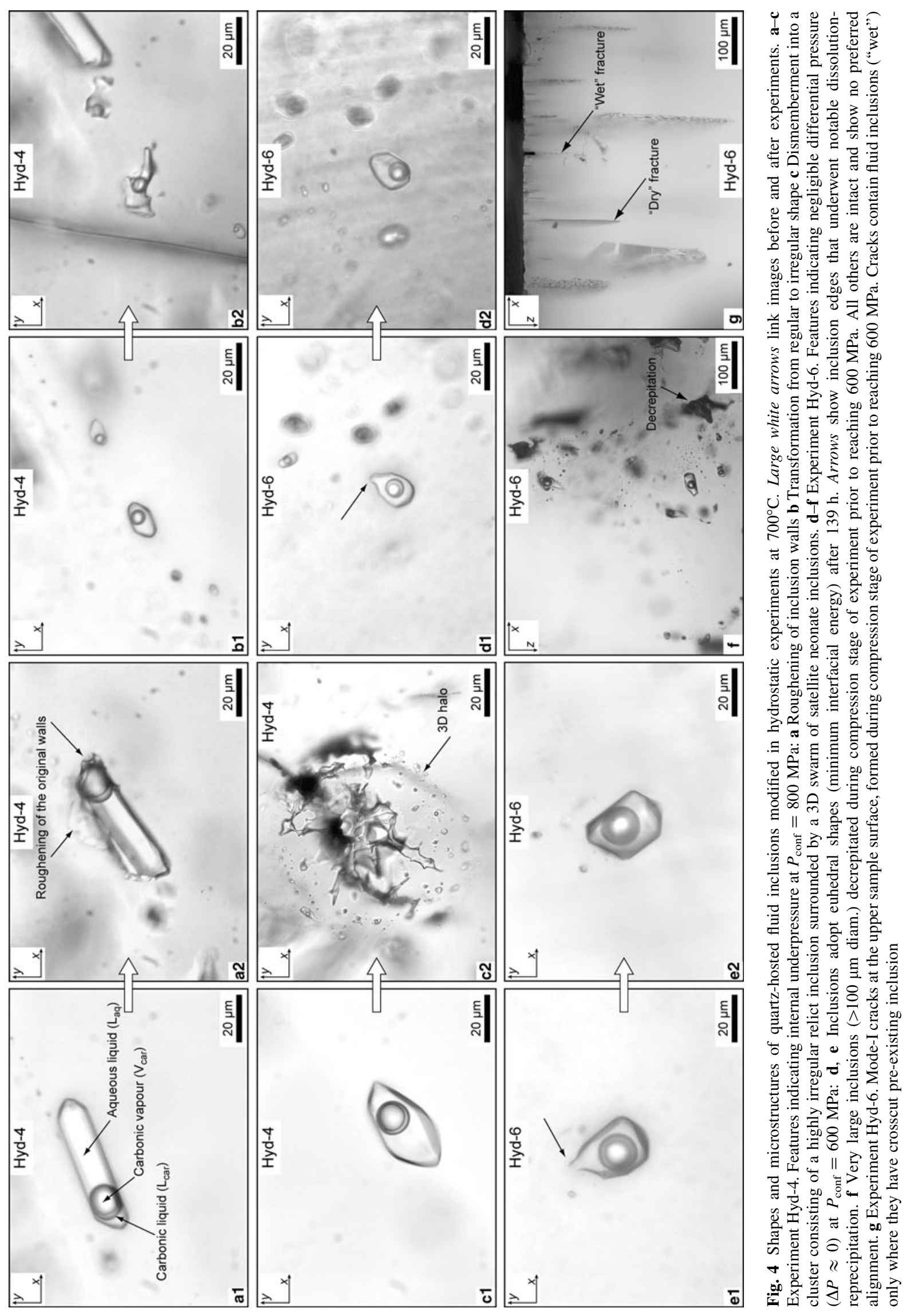


complication of $\mathrm{H}_{2}$ influx. The experiment was buffered with $\mathrm{Fe}_{2} \mathrm{O}_{3}$ and held at $600 \mathrm{MPa}$ for $139 \mathrm{~h}$. Most of the inclusions adopted more euhedral shapes, any previous irregularities in their walls tending to have disappeared (Fig. 4d, e). A few very large inclusions $(>100 \mu \mathrm{m}$ in length) had decrepitated during the compression phase of the experiment and their fluid contents had obviously leaked from the sample along randomly oriented brittle fractures (Fig. 4f). Owing to the loss of fluid the fractures did not heal during the course of the experiment. The intact inclusions show no preferred orientations (Fig. 4f). No changes in microthermometric properties were observed in this buffered experiment.

The collective microstructural and microthermometric observations from the aforementioned hydrostatic experiments indicate that differential hydrostatic pressure on the inclusions in our particular quartz samples is negligible under the conditions of experiment Hyd-6. Accordingly, the subsequent deformation experiments were all performed at $700^{\circ} \mathrm{C}$ with $P_{\text {conf }}=\sigma_{3} \approx 600 \mathrm{MPa}$, under the assumption that this fulfils the condition $\left(P_{\text {inc }}-P_{\text {conf }}\right)=0$.

\section{Uniaxial compression experiments}

The run conditions of six deformation experiments (labelled with prefix Def-) involving deviatoric stress are listed in Table 3. The results of five of these experiments are presented below in order of increasing strain: Def-1 (lowest strain), Def-2 (moderate), Def-3 and Def-5 (medium), and Def-4 (highest). The remaining experiment, Def-6, is reported thereafter because its strain could not be determined, owing to sample disintegration.

In examining the results of the deformation experiments, it is important to bear in mind that owing to the instrumental set-up, the $\sigma_{1}$ axis is parallel to $z$ (vertical) and the $\sigma_{3}$ axis is radially symmetric within the $x-y$ plane: thus, all stresses perpendicular to the $\sigma_{1}$ axis are equal to $\sigma_{3}$.

\section{Lowest strain experiment Def-1}

After being subjected to $\Delta \sigma=92 \mathrm{MPa}$ for $110 \mathrm{~h}$, the strain in this quartz sample was very low $(<0.2 \%)$. The majority of the inclusions survived and could be easily relocated. Incipient shape changes are indicated by ghostlike rims of healed quartz, which mark the original outlines of the precursor inclusions (Fig. 5a). Most inclusions took on more irregular shapes and some became flatter than their precursors (Fig. 5b). A minority of inclusions split up into clusters of several inclusions, each cluster usually comprising a relatively large, irregularly shaped relict inclusion flanked or surrounded by satellite neonates. The threedimensional distribution of inclusions in each cluster defines a plane, and the individual inclusions are linked by areas of healed quartz with abnormally bright light refraction (Fig. 5c).

A vertical section of the sample shows that very large inclusions ( $>100 \mu \mathrm{m}$ length) lost at least some of their contents by decrepitation (Fig. 5d). In such cases, curved brittle fractures emanate from the inclusions over a broad range of orientations, their traces projecting into the $a-c$ plane at angles between 0 and $41^{\circ}$ from the $\sigma_{3}$ axis. Thus, the orientations of these fractures show no obvious control by the crystallographic or applied stress axes. In contrast, smaller inclusions and those located in mode-I fractures (Fig. 5e) have often become elongated and aligned in a uniform orientation. When viewed in $x-z$ section cut parallel to the $a-c$ vertical plane (Fig. 5f), the elongation direction of these inclusions is inclined approximately $5-10^{\circ}$ from the $\sigma_{3}$ axis. The uniform alignment defines a planar fabric.

\section{Moderate strain experiment Def-2}

After $136 \mathrm{~h}$ with $\Delta \sigma=135 \mathrm{MPa}$, the inclusions had acquired highly irregular and flatter shapes, making it difficult to identify them from the location maps. Relict inclusions are surrounded by radial arrays of fluid-filled branches or by planar fans of satellite neonate inclusions (Fig. 5g-h), many of which are monophase (metastable stretched liquid, as described by e.g. Diamond 2003). The planes defined by the branches and neonate inclusions all lie subparallel to $\sigma_{3}$. When the samples are rotated vertically with respect to the light axis of the microscope the zones of healed quartz between the branches and satellite inclusions are seen to have abnormally bright refraction. A vertical section (Fig. 5i) reveals undulatory optical extinction of the quartz in the areas populated by fluid inclusions, whereas the intervening inclusion-free domains maintain their original sharp optical extinction.

\section{Medium strain experiment Def-3}

After being subjected to $\Delta \sigma=162 \mathrm{MPa}$ for $110 \mathrm{~h}$, most of the inclusions had split into clusters of neonates. All the inclusions became highly irregular in shape, mostly with ragged branches reaching out to planar arrays of small neonate inclusions all located on a single plane subparallel to $\sigma_{3}$ (Fig. $6 \mathrm{a}-\mathrm{c}$ ). The neonates often consist of monophase, metastable stretched liquid. Although similar microstructures are observed in the moderate-strain experiment Def-2, here significantly fewer branches radiate from each relict inclusion and the number of isolated neonates is distinctly higher. A vertical $x-z$ section cut along an $a-c$ plane reveals undulatory extinction of the quartz. 


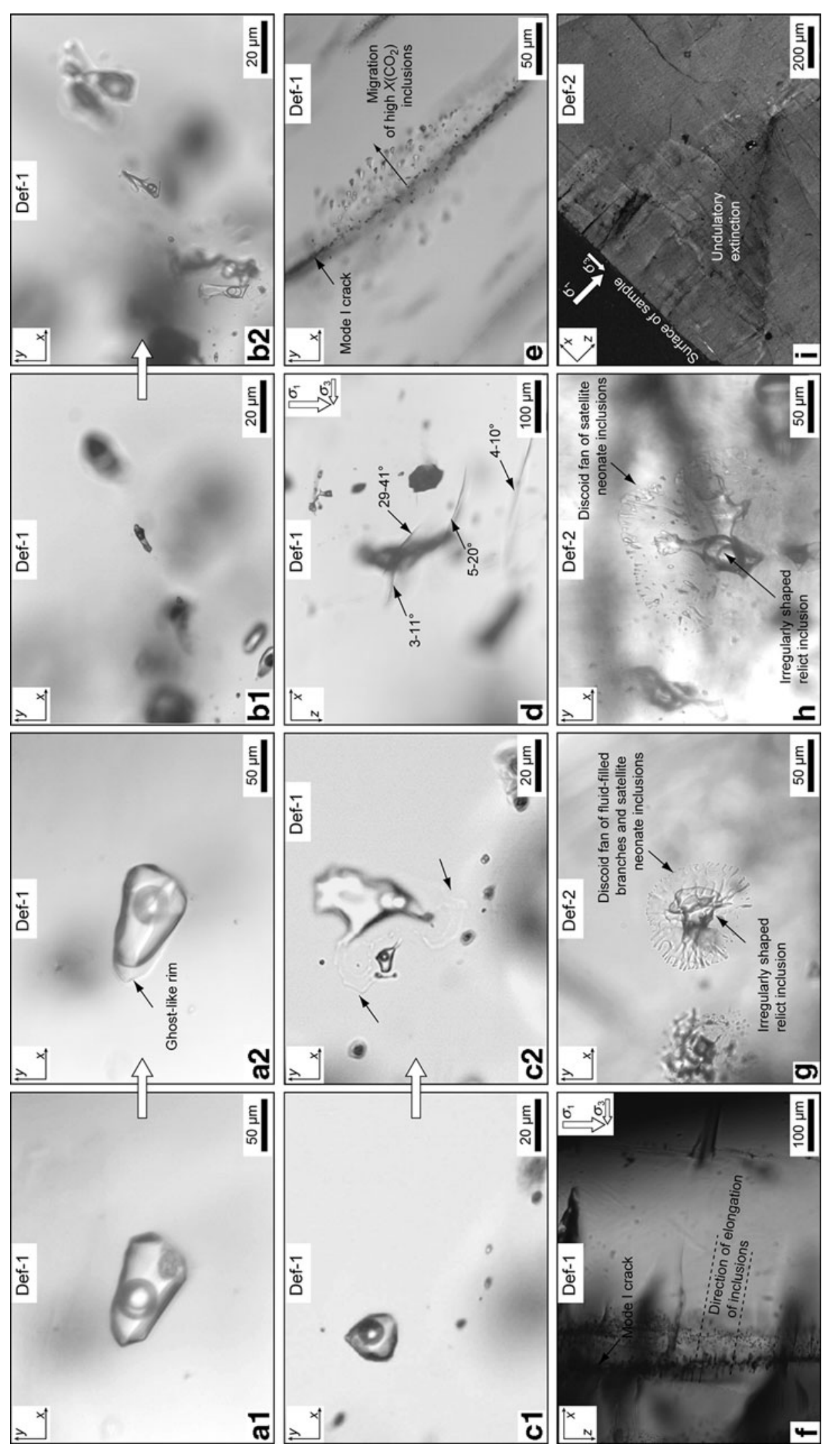

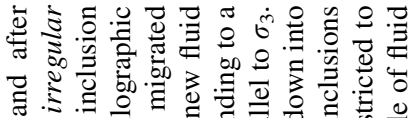

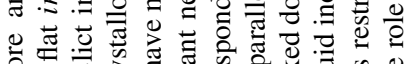

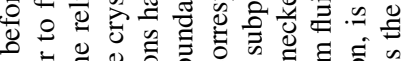

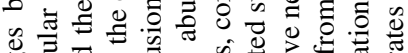

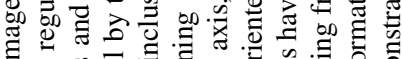

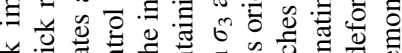

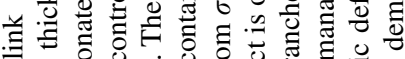

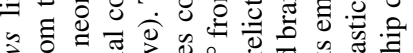

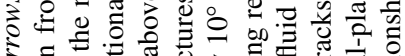
등 on 웝 है

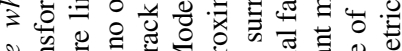

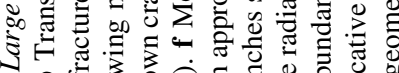

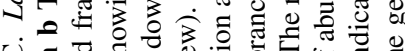

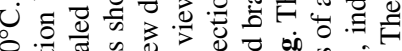

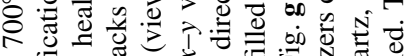

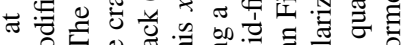

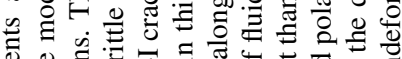
एँ

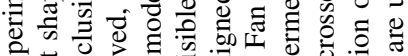
ช.

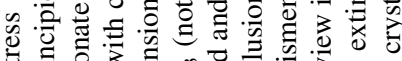

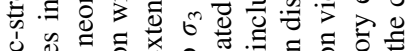

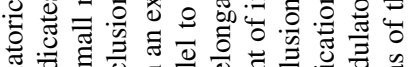
可.

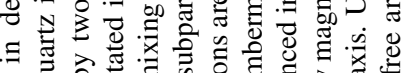

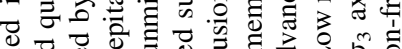

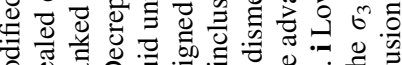
ठ ฮ

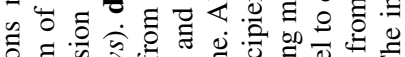

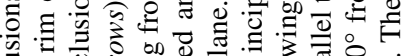

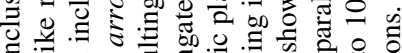
$=$ च च

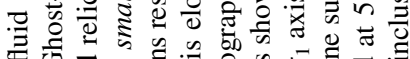
다워

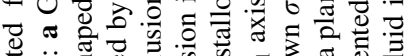

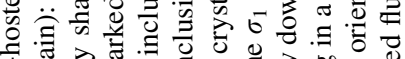

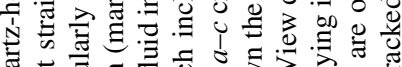

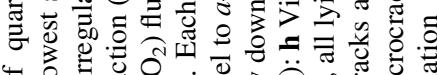

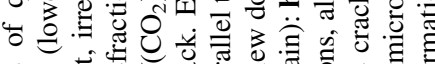

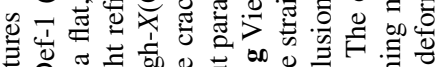

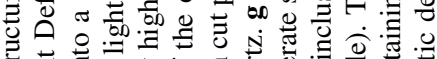

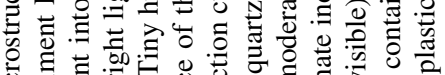

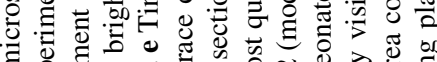

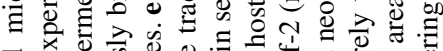

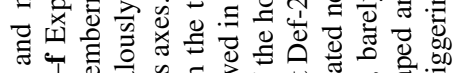
o o

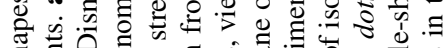

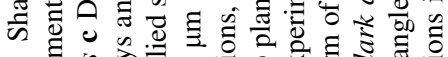

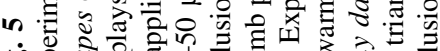

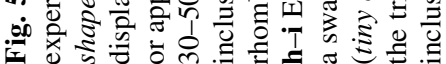




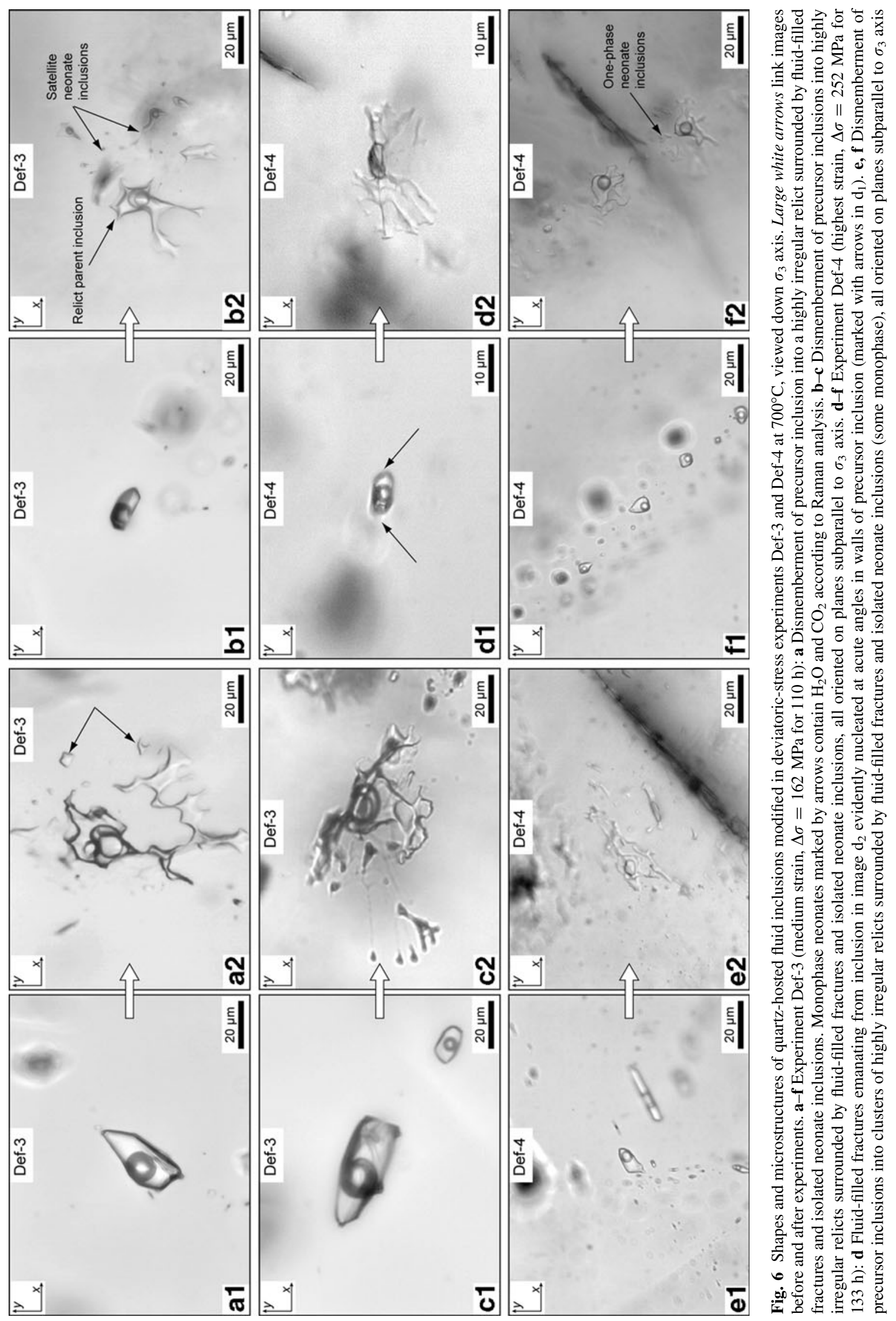




\section{Medium strain experiment Def-5}

After experiencing a relatively high deviatoric stress $(\Delta \sigma=222 \mathrm{MPa})$ for only $12 \mathrm{~h}$, most inclusions showed roughening of their walls and relatively few had formed neonates. Some large relict inclusions are surrounded by planar haloes of neonates, lying subparallel to $\sigma_{3}$. The original shapes of the precursor inclusions were generally preserved, but abundant new microcracks emanate from the angular edges of the inclusions (Fig. $7 \mathrm{~g}-\mathrm{h}$ ). The cracks are strongly aligned. Universal-stage measurements of their orientations (Fig. 8a) reveal that they are strictly confined to $z$ - or $r$-rhomb planes. A vertical section shows strong undulatory optical extinction of the quartz and bands of $c$-axis misorientation.

\section{Highest-strain experiment Def-4}

The sample in experiment Def-4 was subjected for $133 \mathrm{~h}$ to $\Delta \sigma=252 \mathrm{MPa}$, the highest deviatoric stress applied in this study. The resulting strain $(\sim 1 \%)$ induced flattening, elongation and highly irregular shapes in all the inclusions (Fig. 6d-f). As in the lower-strain experiments, most precursor inclusions are dismembered and replaced by clusters of inclusions. Each cluster usually has a large relict inclusion at its centre, surrounded by fans of irregularshaped, fluid-filled branches (Fig. 6d), giving way to haloes of abundant small, isolated neonate inclusions (Fig. $6 \mathrm{f}_{2}$ ). The flattened relicts are larger than the precursors when viewed in the $x-y$ plane (Fig. 6f), but thinner in cross-section. The branches and neonates lie on planes subparallel to $\sigma_{3}$.

A vertical section parallel to $a-c$ reveals undulatory optical extinction of the quartz. Bands of discrete $c$-axis misorientation are observed along three main orientations (Fig. 7a): basal and prismatic planes at roughly $45^{\circ}$ to the $\sigma_{1}$ and $\sigma_{3}$ axes, and rhomb planes at an angle of 5-10 $\sigma_{3}$. At low magnification, the strong preferred alignment of the inclusion clusters imparts a distinctive planar fabric to the sample (Fig. 7b-d). Microcracks originating from fluid inclusions or fluid inclusion clusters also lie in the same planes (Fig. 7b). Universal-stage measurements of the orientations of these planes are plotted in an equal-angle stereographic projection in Fig. 8b. Because the orientation of the sample is known, the planes can be identified unequivocally as $z$ or $r$-rhomb planes.

\section{Experiment Def-6}

In experiment Def-6 $\left(\mathrm{H}_{2}\right.$-buffered, $17 \mathrm{~h}$ duration with $\Delta \sigma=217 \mathrm{MPa}$ ), strong changes in inclusion shapes were observed, similar to those in experiments Def-3 and Def-4: large relict inclusions are surrounded by fans of necked, fluid-filled branches with isolated neonates at their tips. The fans are oriented subparallel to $\sigma_{3}$. Owing to disintegration of the sample during unloading, the bulk strain could not be measured and insufficient material was recovered to make vertical microscope sections.

\section{Fluid inclusions in vertical extensional fractures}

Vertical loading fractures (mode-I cracks) are present in the samples from experiments involving high hydrostatic stresses and in all samples subjected to uniaxial compression. The fractures are oriented parallel to the $\sigma_{1}$ axis (Figs. $5 \mathrm{f}$ and $7 \mathrm{~d}$ ) and they emanate from the upper or lower faces of the samples, penetrating to depths of up to $150 \mu \mathrm{m}$. The traces of the fractures along the sample faces are typically $10-50 \mu \mathrm{m}$ long, with some up to $400 \mu \mathrm{m}$ long, whereas the horizontal apertures of the fractures are only several $\mu \mathrm{m}$ wide.

Typically the fractures are "dry" (Fig. 4g), but some are partly healed and contain myriads of tiny fluid inclusions (Fig. 5e). All fractures that host such inclusions appear to have cut through a pre-existing inclusion in the sample.

The shapes and microstructures of these inclusions in the hydrostatic experiments are quite different from those in the deformation experiments. In the former, the inclusions are generally equant and lie within the fracture trace (Fig. 4g). In the deformed samples, the inclusions have typically migrated away from the fracture trace over distances up to $50 \mu \mathrm{m}$ (Fig. 5e). In addition, all the inclusions are flattened and elongated, with their longest axes uniformly aligned subparallel to $\sigma_{3}$ (Fig. 5f). Thus, the strong preferred orientation of the inclusions in the deformed samples defines a planar fabric lying within a rhomb plane.

\section{Discussion}

The aforementioned results provide a basis to describe the modifications of fluid inclusion shapes and microstructures induced by small degrees of uniaxial shortening. The purpose of the following discussion is to elucidate the mechanisms of these changes with a view to formulating criteria to interpret naturally deformed inclusions.

\section{Changes in fluid inclusion shapes and microstructures}

The shapes and microstructures of fluid inclusions in the hydrostatic experiments are first discussed in the following paragraphs, in order to compare the behaviour of the Brusson quartz samples with previous experimental studies. The observations from the deformation experiments are then discussed as a function of increasing strain. 


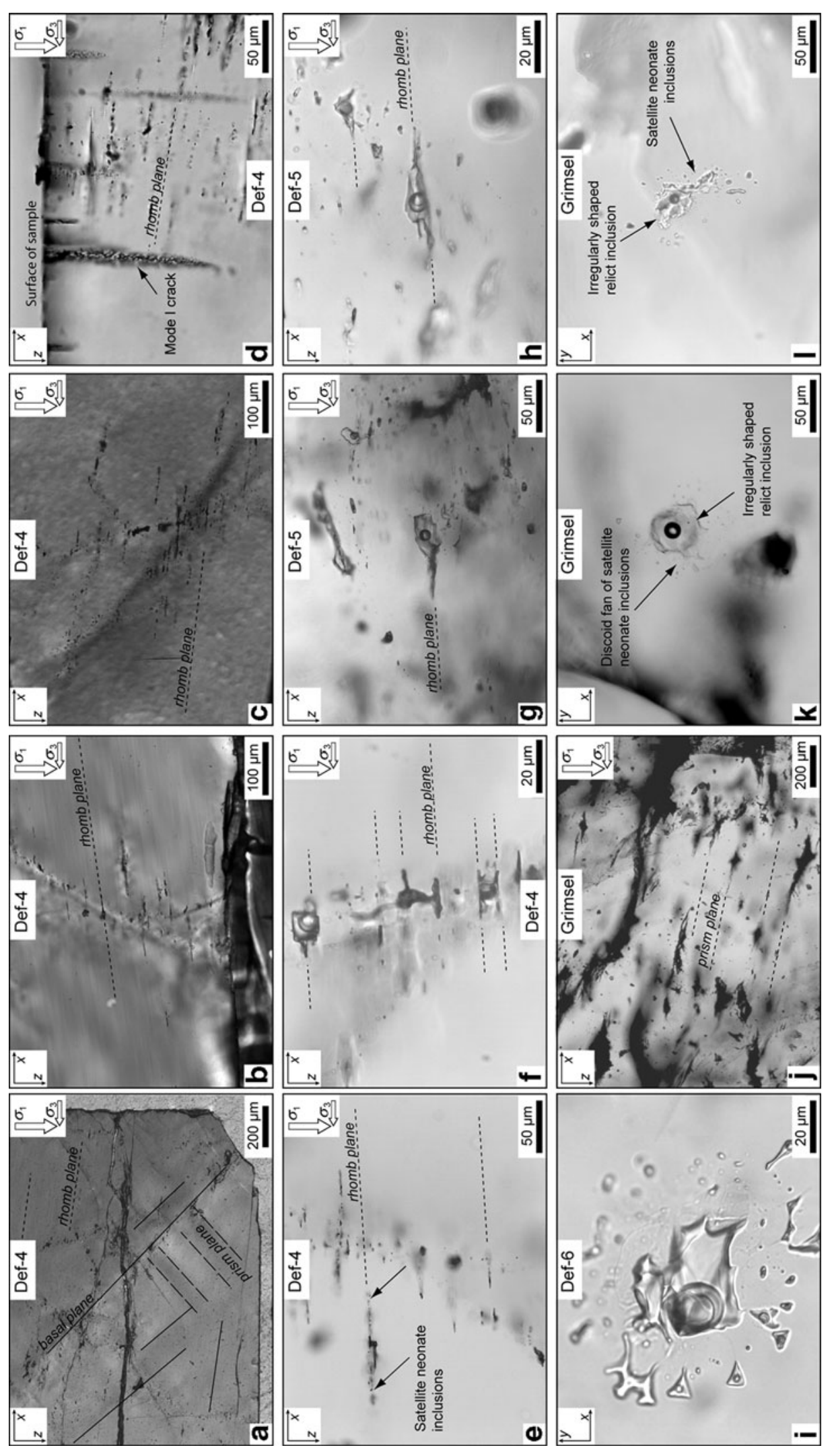

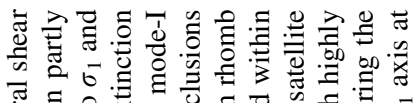

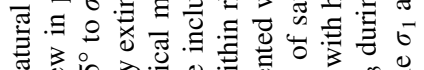

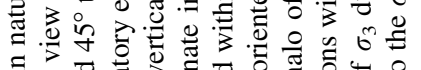

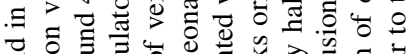

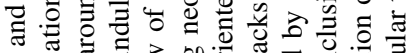

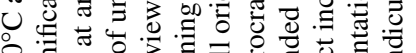

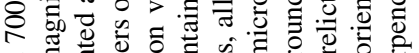

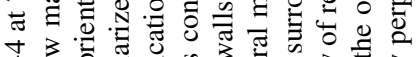

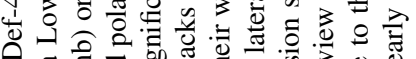

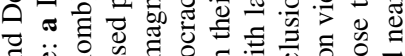
ส

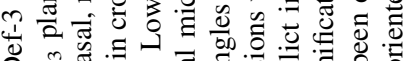

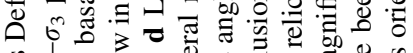

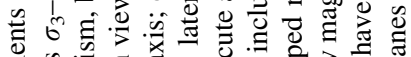

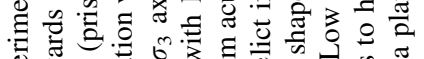

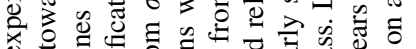

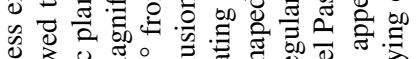

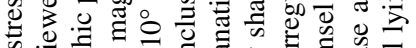

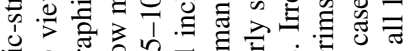

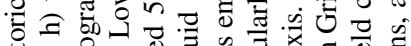
.

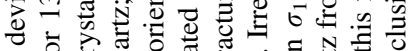
.

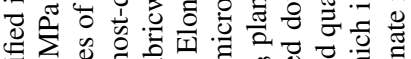
记氜

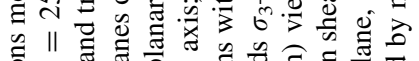

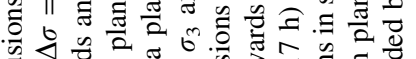

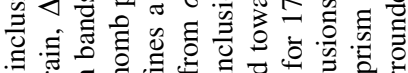

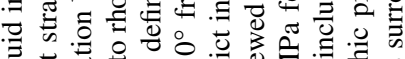

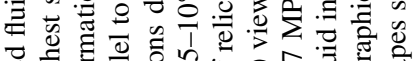

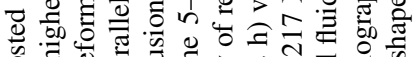

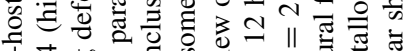

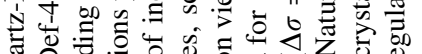
పั

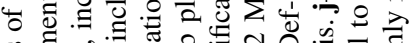
记

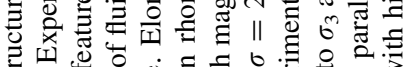

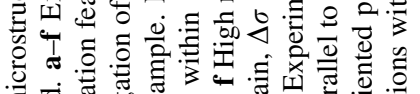

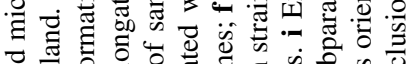

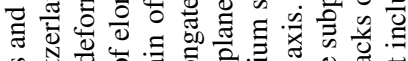
塎.

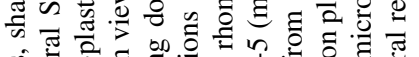

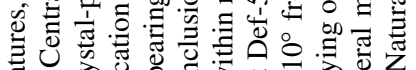

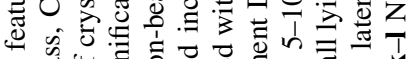

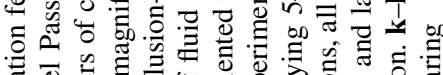

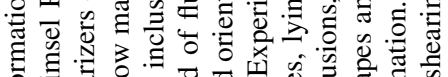

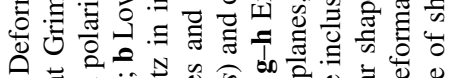
动守论

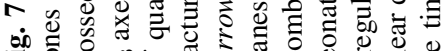

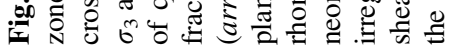


a

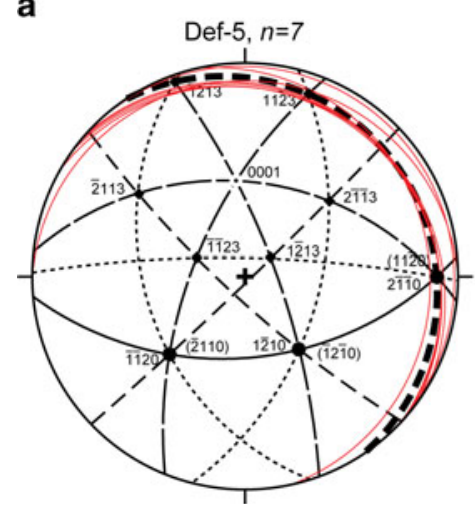

b

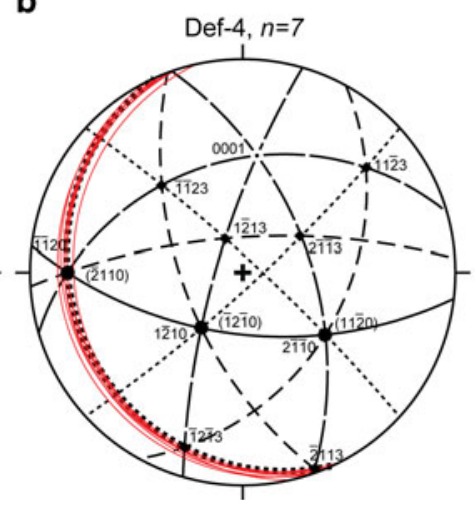

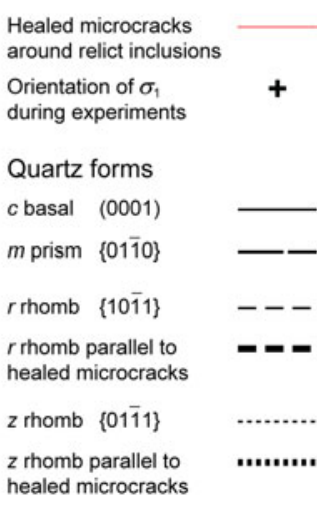

Fig. 8 Relationship between orientations of healed microcracks decorated with neonate inclusions and orientations of crystallographic forms of $\alpha$-quartz, displayed in equal-angle, lower-hemisphere stereonet projections. The stereonets have been rotated by $45^{\circ}$ so that $\sigma_{1}$, which is oriented vertically in the experiments, appears in the centre of the plot. The horizontal plane defined by $\sigma_{3}$ in the experiments is represented by the circumference of the stereonets.

\section{Changes in fluid inclusion shapes and microstructures in hydrostatic experiments}

Under prolonged hydrostatic conditions during which $\Delta P=0$ (e.g. experiments Hyd-5 and Hyd-6), the inclusions gradually adopt euhedral ("negative-crystal") shapes. This spontaneous morphological ripening, involving dissolution and re-precipitation of quartz on the inclusion walls, occurs in response to the universal drive to minimize interfacial free energy. The process has been widely observed in natural and synthetic inclusions (Roedder 1984; Gratier and Jenatton 1984; Bodnar 2003) and was accordingly expected in our experiments.

Application of differential hydrostatic pressure, such that $P_{\text {inc }}<P_{\text {conf }}$, produced distinctive microstructures that are consistent with previous experimental studies. In experiment Hyd-4 the inclusions became dismembered, the relicts acquiring irregular (anhedral) outlines and becoming surrounded by three-dimensional clusters of tiny neonate inclusions (Fig. 4c). Such microstructures are comparable to the "implosion haloes" found by Sterner and Bodnar (1989) when natural or synthetic $\mathrm{CO}_{2}$-free, aqueous inclusions were subjected to experimental underpressures $(\Delta P=-265 \mathrm{MPa})$ at $700^{\circ} \mathrm{C}$ for 2 days. Thus, the present experiments demonstrate that the natural $\mathrm{N}_{2}-\mathrm{CO}_{2}-\mathrm{H}_{2} \mathrm{O}$ $\mathrm{NaCl}$ inclusions in quartz from Brusson behave in accordance with previous studies.

\section{Changes in fluid inclusion shapes and microstructures in deformation experiments}

The deviatoric stress experiments have yielded completely new results. The morphological changes undergo a clear
Healed microcracks (thin lines) were measured with a universal stage to an accuracy of $\pm 5^{\circ}$. a Seven microcracks in deformation experiment Def-5 $(\Delta \sigma=222 \mathrm{MPa}$, medium strain). b Seven microcracks in deformation experiment Def-4 $(\Delta \sigma=252 \mathrm{MPa}$, highest strain). In both samples, the planar fabric defined by the microcracks is clearly parallel to $z$ or $r$ rhomb planes of the host quartz (thickest dashed curves), which lie within 5 to $10^{\circ}$ of the $\sigma_{3}$ plane

progression with increasing strain of the host quartz (Fig. 9). Incipient deformation causes the inclusions to become irregular in outline and to flatten slightly with respect to the precursors. At slightly higher strain, the inclusions generate microcracks, which are preserved as fluid-filled fans and branches defining a flat discoid subparallel to $\sigma_{1}$. The largest diameter of the discoid is significantly larger than that of the precursor. At still higher strains, the radial branches tend to neck down, forming planar haloes of satellite neonate inclusions surrounding or flanking the relicts. The healed quartz between the neonates shows slightly anomalous refraction in transmitted light. Presumably the application of even higher deviatoric stress would lead to complete breakup of the relict inclusions into swarms of still more neonates. However, such an advanced degree of modification was not observed in our experiments.

It is important to note that in the experiments with high deviatoric stresses, all the hundreds of inclusions in each sample changed their shapes, regardless of the size of the precursors. The extent of these modifications is remarkable considering that our experiments were of only short durations (e.g. only $17 \mathrm{~h}$ in the case of Def-6).

Some aspects of the shape changes found in the experiments with deviatoric stresses are similar to those induced by differential hydrostatic pressure. Roughening of inclusion outlines and generation of clusters of satellite neonates are common to both kinds of stress regimes, but the spatial arrangement of the satellites differs. Whereas hydrostatic underpressure produces three-dimensional haloes of satellites (experiment Hyd-4 in this study and Pêcher 1981; Sterner and Bodnar 1989), the deviatoric stress experiments systematically generate arrays that are essentially 


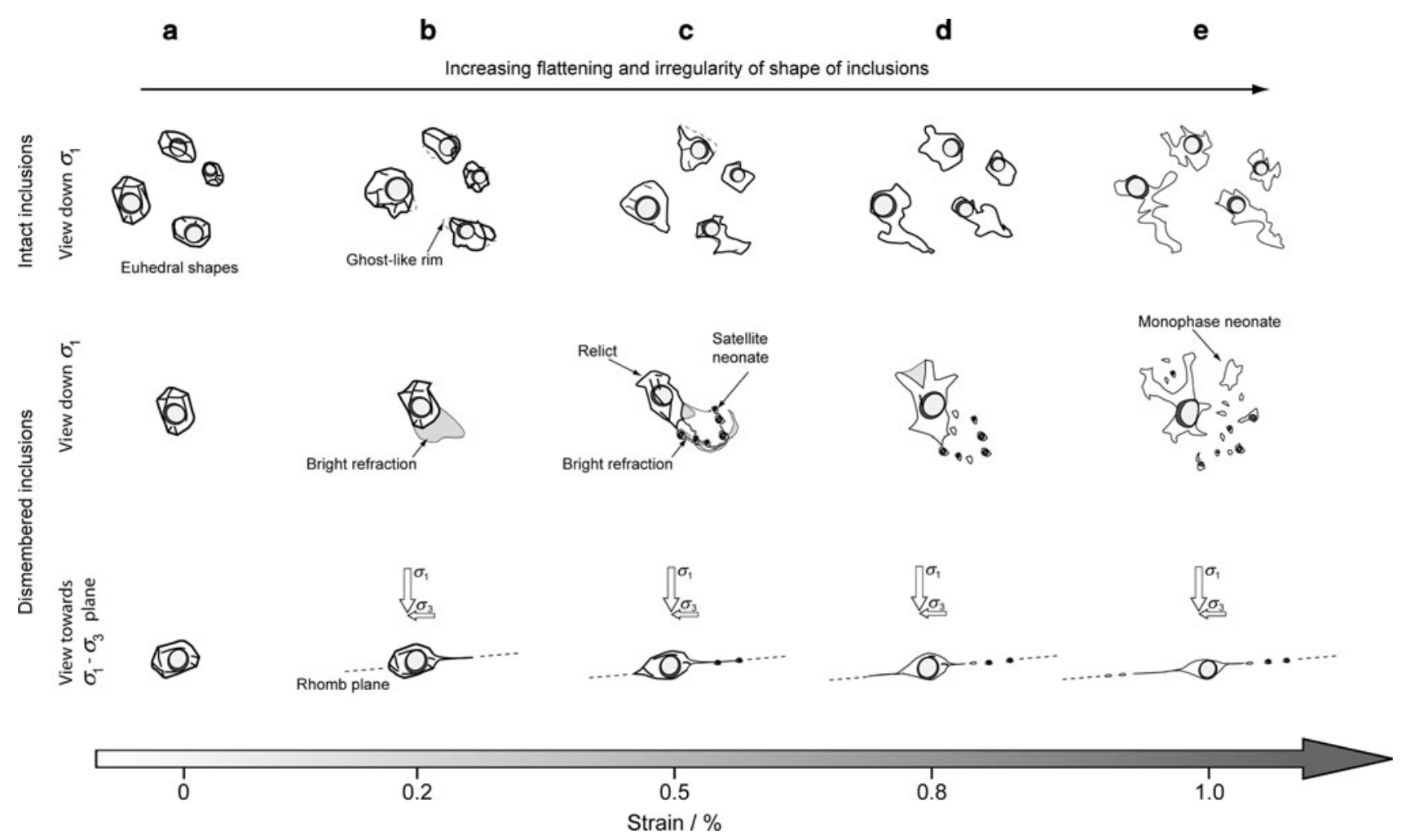

Fig. 9 Schematic synthesis of morphological observations of fluid inclusions deformed in experiments involving deviatoric stresses, ranked according to the nominal strain of the quartz host. With

two-dimensional: flat discoids of fluid-filled branches and satellite neonate inclusions. In individual samples, the hundreds of discoids are all oriented sub-parallel to one another, giving rise to a distinct planar fabric, which is absent in samples modified by differential hydrostatic pressure.

In nature, where elevated temperatures and deviatoric stresses are sustained for much longer periods than in our experiments, we would expect the fine fluid-filled branches surrounding the modified inclusions (e.g. Fig. $5 \mathrm{~g}$ ) to neck down and adopt more equant or even euhedral shapes. Natural samples that have been deformed at high temperature may therefore not show such an abundance of branches, but rather haloes of small, isolated satellite inclusions surrounding the relict parent inclusion. At strains higher than achieved in the present study, when recrystallization of the host crystals occurs, it is expected that even the equant neonates would be destroyed by incorporation in mobile boundaries of sub-grains (e.g. Kerrich 1976; Wilkins and Barkas 1978).

\section{Quartz deformation mechanisms}

Prior to addressing the mechanisms by which the fluid inclusions are modified, it is necessary to identify the increasing strain, the inclusions become flatter, more irrregular in shape, and more dismembered into clusters of relicts and satellite neonate inclusions

mechanisms by which the quartz host crystal was deformed during the experiments. Figure 10 summarizes the various deformation features at the scales of entire samples and of individual inclusions.

Purely brittle features include the vertical mode-I fractures (number 1 in Fig. 10a), the horizontal unloading fractures (number 2 in Fig. 10a), and the decrepitated inclusions surrounded by randomly oriented fractures (number 3 in Fig. 10a). All these cracks are formed below the maximum $P-T$ conditions of the experiments and therefore they are not related to the fluid inclusion modification processes of interest.

The microcracks emanating from individual relict inclusions (number 1 in Fig. 10b) are semi-brittle features. They form at points in the walls of the inclusions that were initially irregularities or angles between crystallographically controlled facets. Nucleation of the cracks at these specific sites is evidently due to stress concentration (e.g. Prezbindowski and Tapp 1991; Burnley and Davis 2004). The thousands of such fractures that have been observed in the samples are all strictly aligned within $z$ or $r$ rhomb planes in the host crystals (Fig. 8), which lie at approximately $85^{\circ}$ to the $\sigma_{1}$ axis and subparallel to $\sigma_{3}$. This contrasts starkly with the orientations of the classically brittle mode-I fractures, all of which lie parallel to $\sigma_{1}$. The 

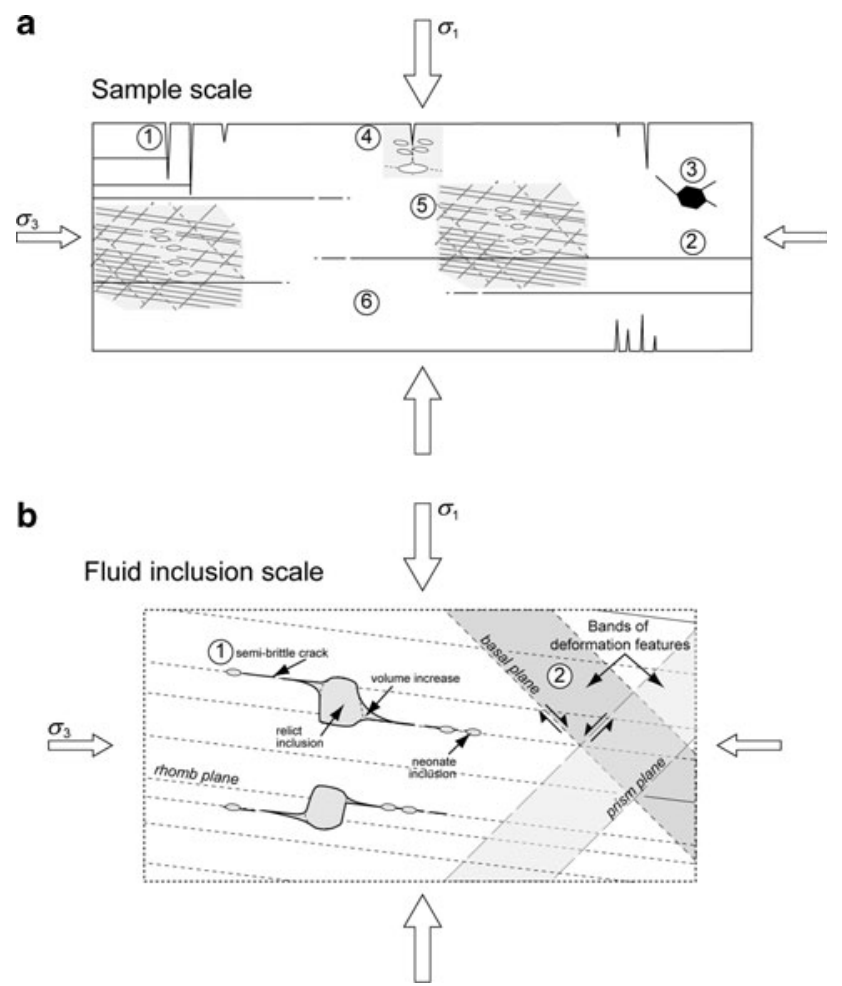

Fig. 10 Schematic summary of quartz deformation features observed after experiments involving deviatoric stresses. a Sample scale: (1) Brittle mode-I compression fractures; (2) Brittle horizontal decompression fractures; (3) Brittle decrepitation of inclusion during compression-heating stage of experiments; (4) Fluid inclusions formed where a mode-I fracture has crosscut a pre-existing inclusion. The inclusions subsequently undergo semi-brittle deformation, including elongation and generation of microcracks parallel to a rhomb plane; (5) Quartz domain originally containing abundant fluid inclusions. Inclusions display semi-brittle deformation including elongation and generation of microcracks parallel to rhomb planes (subparallel to $\sigma_{3}$ axis). Microcracks are mostly healed and decorated with neonate inclusions. Same domain shows crystal-plastic features, including undulatory optical extinction in the microscope and bands of discrete c-axis misorientation along basal and prism planes (inclined $45^{\circ}$ to $\sigma_{1}$ axis); ( 6 ) Quartz domain originally devoid of inclusions shows no crystal-plastic deformation features (optical extinction in microscope is sharp). b Fluid inclusion scale. Enlarged view of domain 5 in Fig. a. (1) Semi-brittle microcracks emanating from relict inclusions are oriented along rhomb planes of quartz (subparallel to $\sigma_{3}$ axis). Healed segments of microcracks host neonate inclusions isolated by dissolution-reprecipitation of quartz; (2) Bands of discrete c-axis misorientation along basal and prism planes (inclined $45^{\circ}$ to $\sigma_{1}$ axis)

preference for microcracking on rhomb planes is apparently unrelated to crystal-plasticity, as the shear component along the rhomb plane is very small in the $\mathrm{O}^{+}$orientation (Schmid factor $<0.09$ ), and so slip of dislocations on the rhomb plane is unlikely. Other glide planes (basal and prism) have higher resolved shear stresses under the conditions of the experiments (Table 1). Bloss and Gibbs (1963) and Ball and Payne (1976) found by experiment that rhomb planes are preferred sites of fracture cleavage in quartz. There are also precedents for this behaviour in nature. For example, Van Daalen et al. (1999) found that cracks in naturally deformed crystals may follow crystallographic planes. As only one plane is favoured in our experiments, all the cracks emanating from the population of inclusions lie parallel to each other, regardless of the variation in initial inclusion shapes. This gives rise to the marked planar fabric (cleavage) in the samples.

Deformation features unequivocally due to crystalplasticity are found in most of the experiments. Samples Def-1, Def-2, Def-3 and Def-5 all display quartz domains with undulatory extinction in the light microscope. In sample Def- 4 bands of discrete $c$-axis misorientation lie at $45^{\circ}$ to the main compressive stresses (Fig. 7a and number 2 in Fig. 10b). The misorientation bands have their traces parallel to prism planes and may be kink-like structures (Mawer and Fitz Gerald 1993). The deformation lamellae (sub)parallel to basal planes (e.g. Fig. 7a and number 2 in Fig. 10b) are usually attributed to high dislocation densities along these features (McLaren et al. 1970; Drury 1993). No new subgrains were recognized in any of the samples. These deformation features are diagnostic of low temperature dislocation glide (e.g. Passchier and Trouw 2005), and their orientations on basal and prism planes are in accord with the maximum resolved stresses lying at $45^{\circ}$ to the $\sigma_{1}$ axis for compression parallel to the $\mathrm{O}^{+}$cut (e.g. Baëta and Ashbee 1969).

Semi-brittle microcracking around the relict inclusions may have occurred either simultaneously or prior to the crystal-plasticity. Microcracking could have been an essentially instantaneous response to the initial loading of the $\sigma_{1}$ compression piston. Alternatively, it could have been a slower process which was active as long the deviatoric stress was applied. Evidence from natural samples (presented in the following paragraphs) favours progressive microcracking concurrent with crystal-plastic deformation. In any case it is clear that the quartz in the experiments has deformed by both semi-brittle and plastic mechanisms.

A key observation is that the diagnostic features of crystal-plasticity occur only in domains where precursor fluid inclusions were abundant (number 5 in Fig. 10a). Domains originally free of inclusions have remained undeformed. The fluid inclusions themselves therefore seem to facilitate crystal-plasticity. In the light of studies on $\mathrm{H}_{2} \mathrm{O}$ weakening (Griggs 1967; Blacic and Christie 1984; Paterson 1989; Fitz Gerald et al. 1991), it appears that the inclusions serve as an in situ source of $\mathrm{H}_{2} \mathrm{O}$ for weakening in an otherwise "dry" crystal. Indeed, in the companion paper (Diamond et al. 2010) evidence is presented that the neonate inclusions have systematically lost $\mathrm{H}_{2} \mathrm{O}$ to the surrounding quartz. It is remarkable that no crystal-plasticity occurs along the rhomb planes which are parted by the microcracks around the relict inclusions. Rather, $\mathrm{H}_{2} \mathrm{O}$ 
loss from the neonate inclusions appears to have triggered dislocation glide along the basal and prism systems that are favoured for the $\mathrm{O}^{+}$orientation and $P-T$ conditions of the experiments (Table 1). Semi-brittle deformation of preexisting inclusions may thus be an essential antecedent to $\mathrm{H}_{2} \mathrm{O}$ weakening and plastic deformation of the quartz (cf. Fitz Gerald et al. 1991).

Model of deformation of fluid inclusions and their quartz host crystals

The earlier discussion and the post-experimental features illustrated in Fig. 10 may be synthesized into a model interpretation of how the fluid inclusions and their host crystals deform. Figure 11 illustrates this model as a function of time and increasing strain for the case of a single fluid inclusion.

Prior to the experiments, the inclusion is under hydrostatic stress (Fig. 11a). During early heating and pressurization of the sample towards the target $P-T$ conditions of the experiment (Fig. 11b), movement of the piston causes unintended, weak axial compression. Because temperature and confining pressure are low, local tensile stresses develop at the boundaries of the sample and at fluid inclusions. The strain at the sample boundaries is accommodated by vertical mode-I fractures (e.g. Paterson 1978). Under axial compression, the elastic deformation of the quartz around the fluid inclusion is anisotropic (Jaeger and Cook 1979) and the inclusion becomes slightly flattened into an ellipsoidal shape. Weak tensile stresses develop at the upper and lower walls of the inclusions and weak radial stresses concentrate at the sides. However, with fluid pressure inside the inclusion close to the confining pressure, the inclusion suffers no permanent deformation (only exceptionally large inclusions in our samples decrepitate via brittle fracturing).

Once the target high $P-T$ conditions of the experiments are attained (Fig. 11c), application of stronger deviatoric stresses to the sample causes greater elastic flattening of the inclusion, higher radial stress concentrations, and increase of fluid pressure inside the inclusions to values above $\sigma_{3}$. As tensile stresses are absent under the high confining pressure (Paterson 1978), the increased radial stress concentrations combine with the elevated fluid pressure to trigger failure via discoid microfractures at the sides of the inclusion (11d). The anisotropy of quartz causes the microcracks not to be aligned perfectly normal to the applied axial stress but instead to follow crystallographic cleavage planes that lie close to the $\sigma_{3}$-plane (rhomb planes in our case). Spontaneous dissolution and reprecipitation of quartz within the rough microcracks (Fig. 11e) heals the cracks and forms neonate inclusions. During this process, migration of $\mathrm{H}_{2} \mathrm{O}$ from the microcracks into the
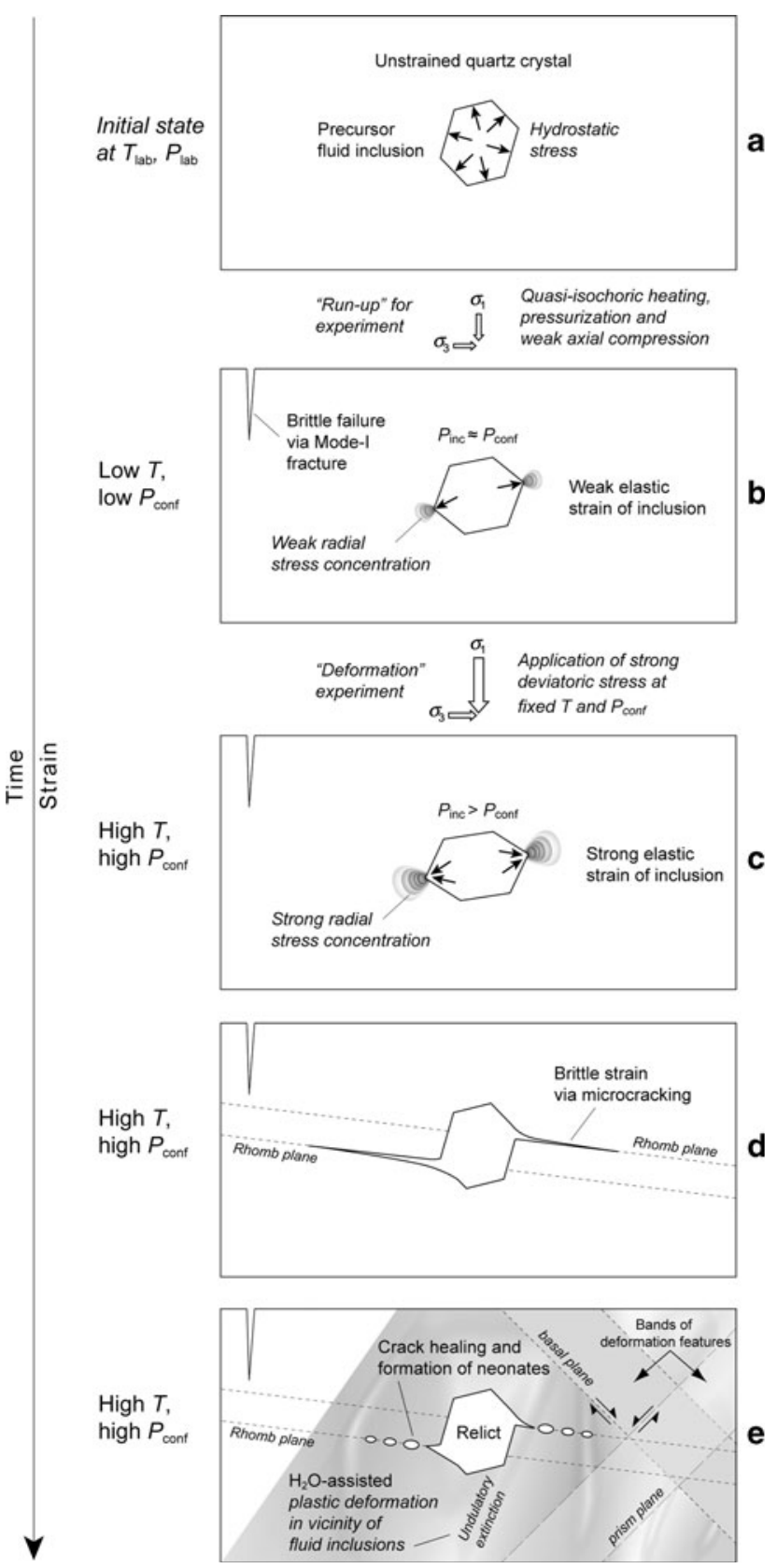

Fig. 11 Schematic illustration (not to scale) of interpreted steps in fluid inclusion deformation that explain the post-experimental observations summarized in Fig. 10. a State prior to experiments. b During heating and pressurization to the target $P-T$ conditions, weak (unintended) axial compression under low $P_{\text {conf }}$ induces Mode-1 fractures in quartz. Inclusion undergoes weak elastic deformation resulting in weak radial stress concentrations. c At high fixed $T$ and $P_{\text {conf }}$, sample is subjected to strong deviatoric stresses via a constant load. Elastic flattening of the inclusion induces high radial stress concentrations. d Points of high stress concentration fail by subcritical microcracking along crystallographic planes of weakness (rhomb planes). e Radial microcracks heal by dissolution-reprecipitation, forming neonate inclusions. Loss of $\mathrm{H}_{2} \mathrm{O}$ from the microcracks to the surrounding quartz promotes plastic deformation, expressed as undulatory optical extinction, deformation lamellae and bands of $c$ axis misorientation. Subsequent cooling and unloading path with attendant horizontal fracturing (cf. Fig. 10) is not shown 
surrounding quartz promotes crystal-plastic deformation, expressed as undulatory optical extinction, deformation lamellae and bands of $c$-axis misorientation. Thus, at the scale of entire samples, only the regions that initially contained fluid inclusions undergo plastic deformation.

Comparison of experiments with naturally deformed samples

A detailed comparison of our results with naturally deformed samples is outside the scope of the present study. However, a cursory comparison with shear-zone hosted quartz veins from the Grimsel Pass, central Switzerland, reveals astonishing similarities in inclusion shapes and microstructures. Figure $7 \mathrm{j}-1$ illustrates the marked planar fabric generated by alignment of microcracks emanating from relict fluid inclusions, and the occurrence of inclusion clusters consisting of irregular relict inclusions flanked by tiny neonates. Similarities also exist in the trends of microthermometric data (to be reported elsewhere).

In view of the much slower rates at which deviatoric stresses accumulate in nature, these microstructures suggest that the microcracking in the experiments may have formed via a slow, progressive process, concurrent with the weak crystal-plastic deformation.

\section{Transferability of experimental results to nature}

An important question is whether the understanding gained from the deformation experiments can be transferred to naturally deformed samples. Four major differences between the experiments and nature may be identified: (1) The experimental samples are brought from a hydrostatic stress regime to uniaxial compression in just a few hours, whereas in nature the rate at which deviatoric stress builds up is likely to be far slower; (2) The deviatoric stresses applied to the single crystals in the experiments are rather high $(90$ to $250 \mathrm{MPa})$. In nature, the values probably do not exceed a few $\mathrm{MPa}$ at $700^{\circ} \mathrm{C}$ when deformed crystal aggregates recrystallize by grain-boundary migration (e.g. Stipp et al. 2002); (3) The nominal strain rates of the experiments $\left(5 \cdot 10^{-9}\right.$ to $\left.9 \cdot 10^{-8} \mathrm{~s}^{-1}\right)$ are some 4 to 6 orders of magnitude higher than those thought to obtain in nature $\left(10^{-13}\right.$ to $10^{-15} \mathrm{~s}^{-1}$; Pfiffner and Ramsay 1982); (4) The experiments are rapidly quenched after experiencing one discrete set of deviatoric stresses (magnitudes and orientations). In contrast, natural samples usually experience a prolonged history of variable magnitudes and orientations of shear deformation, often followed by long periods at elevated temperatures, during which disequilibrium microstructures could perhaps anneal.

Despite these differences, we propose that at least the qualitative results of this study are indeed transferable to nature. The most compelling support of this proposal is the remarkably close similarity between features of the experimentally deformed inclusions and those found in natural quartz veins that have undergone weak shear deformation (Fig. 7j-k). Previous experimental studies, all of which have applied only hydrostatic stresses, have produced systematically different microstructures.

\section{Conclusions}

Experimental application of deviatoric stress at high temperature and high confining pressure produces very low strains in single quartz crystals $(\sim 1 \%)$ but it leads to dramatic modifications of the shapes and microstructures of pre-existing fluid inclusions. Although the experimental samples were deformed under uniaxial compression and in a more brutal fashion than in nature (higher rates of stress application, higher deviatoric stresses and higher strain rates), the modified shapes and microstructures of the inclusions are remarkably similar to those in naturally sheared quartz veins. It therefore appears that the essential features of the experimental products reproduce nature. Accordingly, several principles may be distilled from this experimental study to aid interpretation of naturally deformed samples.

Progressive deformation of the host quartz progressively dismembers the existing inclusions and produces distinctive microstructures. Dismembered inclusions can be distinguished from intact inclusions by their haloes of tiny, newly formed (neonate) inclusions. In contrast to the threedimensional distribution of neonates observed in experiments simulating hydrostatic underpressures, the neonates that formed in response to deviatoric stress are all situated on discoid planes oriented sub-perpendicular to the maximum compressive stress axis, $\sigma_{1}$. This can be easily recognized as a planar fabric at the thin-section scale. Consequently, measurements of the three-dimensional orientation of this fabric in field-oriented samples (e.g. using a universal stage) may reveal the direction of $\sigma_{1}$ during the corresponding deformation.

Since the experimental discovery of "implosion haloes" around fluid inclusions subjected to hydrostatic underpressures (Pêcher 1981; Sterner and Bodnar 1989), natural fluid inclusion samples displaying comparable microstructures have been interpreted to indicate high lithostatic loads (and correspondingly great depths in the crust). The present study has produced inclusion microstructures that at first sight are similar to "implosion haloes", but which instead are due to very low strain of the host quartz induced by deviatoric stress. Such stress-strain conditions commonly occur in shear zones at moderate depths in the crust. Careful observation of the more subtle features of 
deformed fluid inclusions permits the two geological processes to be discriminated.

The modification of the shapes and microstructures of the deformed inclusions seems to involve both semi-brittle and crystal-plastic mechanisms. Microcracking at sites of stress concentration on the inclusion walls is followed by crack-healing and isolation of the neonate inclusions. Their subsequent diffusive loss of $\mathrm{H}_{2} \mathrm{O}$ facilitates crystal-plastic deformation of the adjacent quartz via $\mathrm{H}_{2} \mathrm{O}$-weakening. Thus, crystal-plasticity is observed in the experimental quartz samples only in domains that originally contained abundant fluid inclusions. Domains of the quartz originally devoid of inclusions remain undeformed. Cracking and healing of fluid inclusions under deviatoric stress therefore provides an efficient in situ source of $\mathrm{H}_{2} \mathrm{O}$ to lower the shear strength of quartz and promote deformation of quartz-bearing rocks.

Acknowledgments This study was supported by Swiss National Science Foundation grants 200020-111834 and 200020-122131 to L. W. Diamond. The authors are grateful to Renée Heilbronner and Marco Herwegh for fruitful discussions, to two anonymous journal reviewers for their helpful comments, and to Jacques Touret for editorial advice.

\section{References}

Ayllon F, Bakker RJ, Warr LN (2003) Re-equilibration of fluid inclusions in diagenetic-anchizonal rocks of the Cinera-Matallana coal basin (NW Spain). Geofluids 3(1):49-68

Baëta RD, Ashbee KHG (1969) Slip systems in quartz: I. Experiments. Am Mineral 54:1551-1574

Ball A, Payne BW (1976) The tensile fracture of quartz crystals. J Mater Sci 11:731-740

Blacic JD, Christie JM (1984) Plasticity and hydrolytic weakening of quartz single crystals. J Geophys Res 89:4223-4239

Bloss FD, Gibbs GV (1963) Cleavage in quartz. Am Mineral 48:821838

Bodnar RJ (2003) Re-equilibration of fluid inclusions. In Samson IM, Anderson AJ, Marshall DD Eds.), Fluid Inclusions: Analysis and Interpretation. Min Ass Canada, Short Course Series 32:213-232

Boullier A-M, Michot G, Pêcher A, Barres O (1989) Diffusion and/or plastic deformation around fluid inclusions in synthetic quartz: New investigtions. In: Bridgewater (ed) Fluid movementselement transport and the composition of the deep crust. Kluwer, Dordrecht, pp 345-360

Brooker R, Holloway JR, Hervig R (1998) Reduction in pistoncylinder experiments: The detection of carbon infiltration into platinum capsules. Am Mineral 83:985-994

Burnley PC, Davis KM (2004) Volume changes in fluid inclusions produced by heating and pressurization: an assessment by finite element modelling. Can Min 42:1369-1382

Diamond LW (1990) Fluid inclusion evidence for P-V-T-X evolution of hydrothermal solutions in late-Alpine gold-quartz veins at Brusson, Val d'Ayas, Northwest Italian Alps. Am J Sci 290:912958

Diamond LW (2003) Systematics of $\mathrm{H}_{2} \mathrm{O}$ inclusions. In: Samson IM, Anderson AJ, Marshall DD (eds) Fluid inclusions: analysis and interpretation. Mineralogical Association of Canada, Canada, pp 55-79

Diamond LW, Tarantola A, Stünitz H (2010) Modification of fluid inclusions in quartz by deviatoric stress II: experimentally induced changes in inclusion volume and composition. Contrib Mineral Petrol (this volume)

Doukhan JC, Trépied L (1985) Plastic deformation of quartz single crystals. Bull Min 108:97-123

Drury MR (1993) Deformation lamellae in metals and minerals. In: Boland JN, Fitz Gerald JD (eds) Defects and processes in the solid state: geoscience applications. Elsevier, Amsterdam, pp 195-212

Fitz Gerald JD, Boland JN, McLaren AC, Ord A, Hobbs BE (1991) Microstructures in water-weakened single crystals of quartz. J Geophys Res 96(B2):2139-2155

Gehrig M (1980) Phasengleichgewichte und PVT-Daten ternären Mischungen aus Wasser, Kohlendioxid und Natriumchlorid bis 3 kbar und $550^{\circ} \mathrm{C}$. Doctoral Dissertation, Univ. Karlsruhe

Gratier JP, Jenatton L (1984) Deformation by solution-deposition, and re-equilibration of fluid inclusions in crystals depending on temperature, internal pressure and stress. J Struct Geol 6(1/ 2): $189-200$

Griggs D (1967) Hydrolytic weakening of quartz and other silicates. Geophys J R astr Soc 14:19-31

Hall DL, Sterner SM (1995) Experimental diffusion of hydrogen into synthetic fluid inclusions in quartz. J Metamorph Geol 13:345355

Hirth G, Tullis J (1992) Dislocation creep regimes in quartz. J Struct Geol 14:145-159

Hosieni KR, Howald RA, Scanlon MW (1985) Thermodynamics of the lambda transition and the equation of state of quartz. Am Mineral 70:782-793

Hurai V, Prochaska W, Lexa O, Schulmann K, Thomas R, Ivan P (2008) High-density nitrogen inclusions in barite from a giant siderite vein: implications for Alpine evolution of the Variscan basement of Western Carpathians, Slovakia. J Metamorph Geol 26(4):487-498

Jaeger JC, Cook NGW (1979) Fundamentals of rock mechanics. Chapman and Hall, New York, p 593

Kerrich R (1976) Some effects of tectonic recrystallization on fluid inclusions in vein quartz. Contrib Mineral Petrol 59:195-202

Krüger Y, Diamond LW (2001) $P-V-T-X$ properties of two $\mathrm{H}_{2} \mathrm{O}-$ $\mathrm{CO}_{2}-\mathrm{NaCl}$ mixtures up to $850^{\circ} \mathrm{C}$ and $500 \mathrm{MPa}$ : results of a synthetic fluid inclusion study. ECROFI-XVI (Porto, Portugal) Abstracts volume 241-243

Lister GS, Paterson MS, Hobbs BE (1978) The simulation of fabric development in plastic deformation and its application to quartzite: the model. Tectonophys 45:107-158

Mawer CK, Fitz Gerald JD (1993) Microstructure of kink band boundaries in naturally deformed Cewings range quartzite. In: Boland JN, Fitz Gerald JD (eds) Defects and processes in the solid state: geoscience applications. Elsevier, Amsterdam, pp 49-67

McLaren AC, Turner RG, Bland JN, Hobbs BE (1970) Dislocation structure of the deformation lamellae in synthetic quartz; a study by electron and optical microscopy. Contr Min Pet 29:104-115

Morgan GB, Chou IM, Pasteris JD, Olsen SN (1993) Re-equilibration of $\mathrm{CO}_{2}$ fluid inclusions at controlled hydrogen fugacities. J Metamorph Geol 11:155-164

Morrison-Smith DJ, Paterson MS, Hobbs BE (1976) An electron microscope study of plastic deformation in single crystals of synthetic quartz. Tectonophys 33:43-79

Mukherjee BK, Sachan HK (2009) Fluids in coesite-bearing rocks of the Tso Morari Complex, NW Himalaya: evidence for entrapment during peak metamorphism and subsequent uplift. Geol Mag 146(6):876-889

Passchier CW, Trouw RAJ (2005) Microtectonics. Springer, Heidelberg, p 366 
Paterson MS (1978) Experimental rock deformation. The brittle field. Springer, Berlin, New York 254 pp

Paterson MS (1989) The interaction of water with quartz and its influence in dislocation flow-an overview. In: Shun-ichiro K (ed) Rheology of solids and of the earth. Oxford University Press, Oxford, pp 107-142

Pêcher A (1981) Experimental decrepitation and re-equilibration of fluid inclusions in synthetic quartz. Tectonophys 78:567-583

Pêcher A, Boullier AM (1984) Evolution à pression et température élevées d'inclusions fluides dans un quartz synthétique. Bull Min 107:139-153

Pfiffner OA, Ramsay JG (1982) Constraints on geological strain rates: Arguments from finite strain states of naturally deformed rocks. J Geophys Res 87NB1:311-321

Prezbindowski DR, Tapp JB (1991) Dynamics of fluid inclusion alteration in sedimentary rocks: a review and discussion. Org Geochem 17:131-142

Roedder E (1984) Fluid inclusions. Mineralogical society of America. Rev Mineral 12:646

Schmidt C, Bruhn D, Wirth R (2003) Experimental evidence of transformation plasticity in silicates: minimum of creep strength in quartz. Earth and Planet Sci Lett 205:273-280

Sterner SM, Bodnar RJ (1989) Synthetic fluid inclusions-VII. Re-equilibration of fluid inclusions in quartz during laboratorysimulated metamorphic burial and uplift. J Metamorph Geol 7:243-260

Stipp M, Stünitz H, Heilbronner R, Schmid SM (2002) Dynamic recrystallization of quartz: correlation between natural and experimental conditions. In: De Meer S, Drury MR, De Bresser JHP, Pennock GM (eds) Deformation mechanisms, rheology and tectonics: current status and future perspectives, vol 200. Geological Society, London, pp 171-190
Stöckhert B, Trepmann CA, Massonne HJ (2009) Decrepitated UHP fluid inclusions: about diverse phase assemblages and extreme decompression rates (Erzgebirge, Germany). J Metamorph Geol 27(9):673-684

Van Daalen M, Heilbronner R, Kunze K (1999) Orientation analysis of localized shear deformation in quartz fibres at the brittleductile transition. Tectonophys 303:83-107

Vasyukova OV, Fonarev VI (2006) Experimental modeling of the transformation of $\mathrm{H}_{2} \mathrm{O}-\mathrm{CO}_{2}-\mathrm{CH}_{4}$ inclusions during isobaric cooling and isothermal compression. Geochem Internat 44(12): 1170-1180

Vernooij MGC, den Brok B, Kunze K (2006) Development of crystallographic preferred orientations by nucleation and growth of new grains in experimentally deformed quartz single crystals. Tectonophys 427:35-53

Vityk MO, Bodnar RJ (1995) Textural evolution of synthetic fluid inclusions in quartz during re-equilibration, with applications to tectonic reconstruction. Contrib Mineral Petrol 121:309-323

Vityk MO, Bodnar RJ, Schmidt CS (1994) Fluid inclusions as tectonothermobarometers-relation between pressure-temperature history and reequilibration morphology during crustal thickening. Geology 22(8):731-734

Vityk MO, Bodnar RJ, Dudok IV (1996) Fluid inclusions in "Marmarosh diamonds": evidence for tectonic history of the folded Carpathian mountains, Ukraine. Tectonophys 255(1-2): 163-174

Wilkins RWT, Barkas JP (1978) Fluid inclusions, deformation and recrystallization in granite tectonites. Contrib Mineral Petrol 65:293-299 